CENTRE for ECONOMIC

$P$ E R F O R M A N C E

CEP Discussion Paper No 743

(Revised)

December 2006

\title{
Search and Matching Frictions and Optimal Monetary Policy
}

Job Market Paper

Carlos Thomas

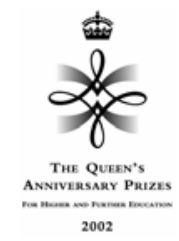




\begin{abstract}
I analyze optimal monetary policy in an economy with search and matching frictions in the labor market and staggered nominal wage and price contracts. In this framework, as opposed to the standard New Keynesian model, preset nominal wages need not have any effect on existing employment relationships. However, staggered bargaining of nominal wages distorts aggregate job creation and creates inefficient dispersion in hiring rates across firms. Targeting zero inflation (the optimal policy in the standard New Keynesian model) only magnifies these distortions. The optimal policy allows for non-zero inflation in response to real shocks, so as to reduce the rigidity of real wages. Quantitatively, the case against price stability as the sole goal of monetary policy turns out to be important.
\end{abstract}

Keywords: search and matching, New Keynesian, staggered nominal wage bargaining JEL Classifications: E52, E32, J40

This paper was produced as part of the Centre's Macro Programme. The Centre for Economic Performance is financed by the Economic and Social Research Council.

\title{
Acknowledgements
}

Special thanks to Kosuke Aoki, Nobu Kiyotaki and Chris Pissarides for their guidance, encouragement and support. Thanks also to Gianluca Benigno, Kevin Sheedy, Alan Manning, Jordi Gali, Paul Castillo, Mariano Bosch, Francesco Zanetti and Kalin Nikolov for very helpful comments. All remaining errors are mine.

Carlos Thomas is with the Economics Department, London School of Economics.

Email: c.thomas1@1se.ac.uk

Published by

Centre for Economic Performance

London School of Economics and Political Science

Houghton Street

London WC2A 2AE

All rights reserved. No part of this publication may be reproduced, stored in a retrieval system or transmitted in any form or by any means without the prior permission in writing of the publisher nor be issued to the public or circulated in any form other than that in which it is published.

Requests for permission to reproduce any article or part of the Working Paper should be sent to the editor at the above address.

(C) C. Thomas, submitted 2006

ISBN 0753020491 


\section{Introduction}

The search and matching paradigm has become a powerful tool for the analysis of unemployment and the labor market. ${ }^{1}$ It is able to accommodate a wide range of labor market policies and analyze their long-run effect on unemployment and wages. ${ }^{2}$ When incorporated into otherwise standard real business cycle (RBC) models, it has been shown to improve significantly their empirical performance. ${ }^{3}$ More importantly, it allows to analyze the cyclical behaviour of unemployment, vacancies and job flows, important phenomena which general equilibrium models based on Walrasian labor markets are not designed to address.

Parallel to this literature, the New Keynesian model has emerged as the standard model of the monetary transmission mechanism. In its simplest version, the New Keynesian model incorporates monopolistic competition and staggered price setting into the standard RBC model. ${ }^{4}$ Because it is based on optimizing behaviour, it allows for rigorous welfare analysis of alternative monetary policy rules. This, together with its simplicity and empirical success, has allowed the model to become the workhorse for the analysis of optimal monetary policy. ${ }^{5}$ However, it has inherited the RBC model's inability to say anything about unemployment and other key labor market variables. This has led some researchers to introduce search and matching frictions into the New Keynesian model, with a view to improving its descriptive power. ${ }^{6}$ Most notably, these hybrid models allow to study the joint dynamics of unemployment and inflation, i.e. the Phillips curve.

However, up to date almost no work has been done in analyzing optimal monetary policy in a New Keynesian framework with search and matching frictions. ${ }^{7}$ This

\footnotetext{
${ }^{1}$ The search and matching framework was developed by Diamond (1982), Mortensen (1982) and Pissarides (1985). For a simple exposition, see Pissarides (2000, Ch. 1).

${ }^{2}$ See e.g. Mortensen and Pissarides (2003).

${ }^{3}$ See Merz (1995), Andolfatto (1996), Den Haan et al. (2000) and Hairault (2002) and Gertler and Trigari (2006).

${ }^{4}$ The New Keynesian model was developed by the work of Kimball (1995) and Yun (1996), building on Calvo's (1983) mechanism of staggered price setting.

${ }^{5}$ See King and Wolman (1999), Clarida et al. (1999) and Woodford (2003) for extensive analyses of monetary policy in New Keynesian models. See Gali and Gertler (1999), Sbordone (2001) and Gali et al. (2001) for assessments of the model's ability of explain inflation dynamics in the US and other industrialized economies.

${ }^{6}$ See Cheron and Langot (2000), Walsh (2003, 2005), Trigari (2003,2005), Moyen and Sahuc (2005), Christoffel and Linzert (2005), Blanchard and Gali (2006) and Domenech et al. (2006). Cooley and Quadrini (1999) consider a limited participation model of money, rather than staggered prices.

${ }^{7}$ The only exception that I am aware of is the independent work by Blanchard and Gali (2006). The differences between both papers are explained below in this section.
} 
paper is an attempt to fill this gap. In addition to staggered price setting by firms, I also incorporate staggered bargaining of nominal wages between firms and workers. ${ }^{8}$ Since staggering of nominal wages is an established fact of virtually all industrialized economies, it makes little sense to analyze monetary policy in a model with staggered prices only. ${ }^{9}$

Search frictions introduce an explicit distinction between the two margins of labor, because adjusting the extensive margin is costly and time-consuming. Efficiency in this framework therefore requires stabilizing both employment (equivalently, unemployment) and hours per employee around their efficient paths. In addition, dispersion in relative prices or wages across firms must be avoided.

My first result concerns the benchmark case in which all wages are Nash-bargained in every period. In this case, I show that, provided the economy's steady state is efficient, the central bank can replicate the efficient equilibrium by keeping the price level constant. This way, it can eliminate the distortionary effects of price stickiness, because those firms that cannot reset prices would not want to change them anyway.

The empirically relevant case however is the one in which only a fraction of firms renegotiate nominal wages. Staggered bargaining of nominal wages creates two types of distortion. First, the stickiness of nominal wages leads to real wage rigidity in response to real shocks; since firms' incentives to post vacancies depend on the real wages to be paid to the new workers, aggregate job creation is inefficient. Second, the failure of some nominal wages to adjust leads to wage dispersion, which in turn leads to inefficient dispersion in hiring rates across firms. Targeting zero inflation only magnifies these distortions. The optimal policy commitment therefore implies temporary deviations from zero inflation in response to real shocks. The central bank uses price inflation so as to accelerate the converge of actual real wages towards their flexible-wage (Nash) counterparts. This allows the central bank to reduce the distortions arising from nominal wage stickiness. First, there is less inefficiency in aggregate job creation and therefore in the unemployment path. ${ }^{10}$ Second, if real wages are closer to their flexible-wage counterparts, renegotiating firms will change their nominal wages by a smaller amount, thus reducing wage dispersion and the subsequent dispersion in hiring rates. I show that, for a reasonable calibration of the model, the welfare loss incurred by society under the zero inflation policy is

\footnotetext{
${ }^{8}$ Gertler and Trigari (2006) have introduced staggered bargaining of real wages in a real business cycle framework with search and matching frictions, with the purpose of reconciling the smooth behaviour of real wages with the high volatility of labor market activity in the US.

${ }^{9}$ For evidence on staggering of nominal wages in the US and other industrialized economies, see Taylor (1999) and the references therein.

${ }^{10} \mathrm{I}$ assume exogenous job destruction, such that changes in unemployment are due to changes in job creation only.
} 
approximately twice as large as under the optimal commitment.

The suboptimality of the zero inflation policy in this framework contrasts with the policy recommendation of the standard New Keynesian model. In the latter, provided the steady state is efficient (or nearly efficient), the optimal policy commitment consists precisely of keeping the price level constant, not just in the long run but also in response to the kinds of real shocks (to technology, preferences and government expenditure) that are thought to be the main sources of business cycle fluctuations. ${ }^{11}$ This policy prescription has been called 'the case for price stability'. ${ }^{12}$

In this respect, an important predecessor to my paper is the work of Erceg, Henderson and Levin (2000). In direct analogy with the mechanism for staggered price setting in goods markets, these authors assume that households are monopolistic suppliers of labor who set their own wages at random intervals, and then let firms decide how much labor they want to buy. They show that wage staggering distorts aggregate labor allocations and creates inefficient dispersion in labor requirements across firms. As a consequence, zero inflation is not optimal, for reasons that are similar to those discussed above. However, as emphasized by Goodfriend and King (2001), there is a fundamental asymmetry between labor markets, where most employment relationships are long-term, and goods markets, where spot transactions prevail. But in a context of on-going employment relationships, sticky wage models are subject to the well-known Barro (1977) critique: preset nominal wages should not distort efficient employment relationships, because both parties can always renegotiate the labor-wage package in a way that makes the two of them better off relative to the situation without renegotiation.

Search frictions serve a double purpose in my model. First, it motivates the existence of on-going employment relationships, by creating a joint surplus for firm and worker which is in their mutual interest to keep. Second, it allows me to analyze the distortionary effect of staggered nominal wages in a way that is free of Barro's critique. Search frictions create a bargaining set, i.e. a wedge between the firm's and the worker's reservation wage. As emphasized by Hall (2005), even if the wage cannot be changed, so long as it remains inside the bargaining set it will not lead to inefficient job loss. Barro's critique also applies to the intensive margin of labor, hours per employee. Again, I avoid imposing arbitrary distortions on employment relationships by assuming that hours are determined in a privately efficient way, by maximizing the joint match surplus; this makes hours independent of the wage.

\footnotetext{
${ }^{11}$ See e.g. King and Wolman (1999) and Woodford (2003, section 6.3). Woodford (2003, section 6.4) discusses reasons why price stability may not be optimal, including large steady-state distortions.

${ }^{12}$ See e.g. Goodfriend and King (2001) and Woodford (2003, section 6.3).
} 
Therefore, preset nominal wages in my model do not affect existing employment relationships. However, they do affect vacancy posting by firms and therefore the rate at which employment relationships are formed. I conclude that my framework provides a case against strict price stability while at the same time avoiding Barro's critique.

A second important difference relative to Erceg et al. (2000) is the following. In the Erceg et al. (2000) model, stabilizing the output gap (i.e. the gap between actual and efficient output) is equivalent to stabilizing a weighted average of price and wage inflation. Since the latter are quantitatively the main sources of distortion in that model, it follows that closing the output gap is nearly optimal for any degree of price and wage stickiness. In my model, conditional on the employment stock, stabilizing output is equivalent to stabilizing hours per worker. The latter are distorted by price stickiness, as well as by inefficient vacancy posting (through the resource constraint), but not by wage stickiness. If vacancy posting costs are small as a fraction of output, then closing the output gap is approximately equivalent to eliminating inflation. Not surprisingly, my numerical results suggest that, for empirically plausible degrees of wage stickiness, output gap targeting may not be a desirable policy either.

To my knowledge, the only paper that analyzes optimal monetary policy in a New Keynesian model with search and matching frictions is the independent work by Blanchard and Gali (2006). These authors present a simple integration of the New Keynesian and the search and matching models where equilibrium dynamics can be solved analytically. They also present an interesting comparison of the effect of alternative monetary policy rules on the US as opposed to the EU economy, where average job finding and separation rates are lower and unemployment therefore is more persistent. When wages are Nash bargained in every period and the economy's steady state is efficient, zero inflation is the optimal policy, as is the case here. However, Blanchard and Gali depart from the flexible-wage benchmark by assuming the existence of a wage norm (i.e. a constant real wage), rather than by assuming staggered nominal wage bargaining as I do here. ${ }^{13}$ They then consider wage rules where the actual real wage is a weighted average of the Nash wage and the wage norm. As emphasized by Gertler and Trigari (2006), an advantage of assuming staggered wage contracts a la Calvo (1983) is that the parameter regulating wage stickiness (the fraction of wages that remain constant each period) can be calibrated empirically, contrary to an arbitrary partial adjustment coefficient in a wage equation. More importantly, I show that replacing staggered wages with a wage equation based on a symmetric wage norm underestimates the extent to which the zero inflation policy

\footnotetext{
${ }^{13}$ The wage norm was introduced by Hall (2005). It has been subsequently used by a number of authors, including Krause and Lubik (2005) and Christoffel and Linzert (2005).
} 
is suboptimal, because in the latter case there is no wage dispersion and therefore no welfare loss resulting from dispersion in hiring rates.

The remainder of the paper is organized as follows. Section 2 presents the model. Section 3 obtains the efficient equilibrium in this economy. Section 4 shows how the central bank can replicate the efficient equilibrium when wages are Nash bargained in every period. Section 5 introduces staggered bargaining of nominal wages. Section 6 casts the monetary policy problem in a linear-quadratic representation, which allows an easier understanding of the central bank's stabilization goals and trade-offs. The model is then calibrated and simulated both under the zero inflation policy and the optimal commitment. The implications of targeting the output gap, as well as replacing staggered wages with a wage norm, are discussed in section 7 . Section 8 concludes.

\section{The model}

The following model is a general equilibrium extension of Pissarides' (1985) model of search and matching frictions in the labor market with exogenous job destruction. I consider explicitly both margins of labor: employment and hours. The main structure of the model is very similar to Andolfatto's (1996) business cycle model. In addition, I assume staggered price and wage setting in order to introduce a non-trivial role for monetary policy.

In this economy, the presence of search frictions in the labor market prevents some jobseekers from finding jobs and some vacant positions from being filled in each period. When a firm finds a suitable job applicant, we say that a match has been formed. The number of matches $m_{t}$ formed in period $t$ is given by the following matching function,

$$
m_{t}=m\left(v_{t}, u_{t}\right)
$$

where $v_{t}$ is the total number of vacancies posted by firms and $u_{t}$ is the total number of unemployed workers. Normalizing the labor force to $1, u_{t}$ also represents the unemployment rate. The function $m$ is strictly increasing and strictly concave in both arguments. Assuming constant returns to scale in the matching function, ${ }^{14}$ the matching rate for unemployed workers, or job-finding rate, is given by

$$
\frac{m_{t}}{u_{t}}=m\left(\frac{v_{t}}{u_{t}}, 1\right) \equiv p\left(\theta_{t}\right)
$$

\footnotetext{
${ }^{14}$ See Petrongolo and Pissarides (2001) for empirical evidence of constant returns to scale in the matching function for several industrialized economies.
} 
where $\theta_{t} \equiv v_{t} / u_{t}$ is an indicator of labor market tightness. The function $p(\theta)$ is increasing in $\theta$ : the tighter the labor market, the easier it is for unemployed workers to find jobs. Similarly, the matching rate for vacancies is given by

$$
\frac{m_{t}}{v_{t}}=m\left(1, \frac{1}{v_{t} / u_{t}}\right) \equiv q\left(\theta_{t}\right)
$$

The function $q(\theta)$ is decreasing in $\theta$ : the higher the number of vacancies relative to the stock of job-seekers, the more difficult it is for firms to fill vacant positions. Notice that $p\left(\theta_{t}\right)=\theta_{t} q\left(\theta_{t}\right)$.

\subsection{Households}

In the presence of unemployment risk, we may observe differences in consumption levels between employed and unemployed consumers. However, under the assumption of perfect insurance markets, consumption is equalized across consumers. This is equivalent to assuming the existence of a large representative household, as in Merz (1995). In this household, a fraction $n_{t}=1-u_{t}$ of its members are employed. The remaining fraction $u_{t}$ search for jobs. All members pool their income so as to ensure equal consumption across members.

Employed members separate from their jobs at the exogenous rate $\lambda$, whereas unemployed members find jobs at the rate $p\left(\theta_{t}\right)$. Therefore, the household's employment rate evolves according to the following law of motion,

$$
n_{t+1}=(1-\lambda) n_{t}+p\left(\theta_{t}\right)\left(1-n_{t}\right)
$$

Equation (1) is the Beveridge curve, which describes the relationship between vacancies and the unemployment rate.

At the start of period $t$, the household receives a nominal interest rate $i_{t-1}$ on its holdings of one-period nominal bonds, $B_{t-1}$. I assume that $i_{t}$ is directly controlled by the central bank. Aggregate nominal profits from the firm sector, $\Pi_{t}$, are reverted to the representative household in a lump-sum manner. In addition, the household owns a fixed endowment of physical capital, $\bar{k}$, which is rented to firms at the perfectly competitive real rate $r_{t}$. Members employed at firm $i \in[0,1]$ earn a nominal wage $W_{i t}$. Denoting by $n_{i t}$ the number of workers in firm $i$, the total wage income of the representative household is given by $\int_{0}^{1} n_{i t} W_{i t} d i$. Wage income is pooled with the rest of income sources and used to purchase bonds as well as units of the Dixit-Stiglitz consumption basket,

$$
c_{t} \equiv\left(\int_{0}^{1} c_{j t}^{\frac{\gamma-1}{\gamma}} d j\right)^{\frac{\gamma}{\gamma-1}}
$$


where $\gamma>1$ measures the elasticity of substitution across differentiated goods $j \in$ $[0,1]$. Cost minimization implies that the nominal cost of consumption is given by $P_{t} c_{t}$, where

$$
P_{t} \equiv\left(\int_{0}^{1} P_{j t}^{1-\gamma} d j\right)^{\frac{1}{1-\gamma}}
$$

is the corresponding price index. Therefore, the household's budget constraint is given by

$$
\left(1+i_{t-1}\right) \frac{B_{t-1}}{P_{t}}+\int_{0}^{1} n_{i t} \frac{W_{i t}}{P_{t}} d i+r_{t} \bar{k}+\frac{\Pi_{t}}{P_{t}} \geq c_{t}+\frac{B_{t}}{P_{t}} .
$$

The household derives utility $u\left(c_{t}\right)$ from consumption, where $u$ is strictly increasing and concave. Employed members suffer disutility $v\left(h_{t}\right)$ from working $h_{t}$ hours, where $v$ is strictly increasing and convex; they also incur a fixed utility cost $b$, e.g. time spent commuting to work. Therefore, the representative household chooses consumption and bond holdings to solve ${ }^{15}$

$$
H\left(n_{t}, B_{t-1}\right)=\max _{c_{t}, B_{t}}\left\{u\left(c_{t}\right)-n_{t}\left[v\left(h_{t}\right)+b\right]+\beta E_{t} H\left(n_{t+1}, B_{t}\right)\right\},
$$

subject to (1) and (2). The solution to this problem is given by the standard consumption Euler equation,

$$
u^{\prime}\left(c_{t}\right)=\beta\left(1+i_{t}\right) E_{t}\left[\frac{P_{t}}{P_{t+1}} u^{\prime}\left(c_{t+1}\right)\right] .
$$

Therefore, the central bank can control aggregate consumption $c_{t}$ by means of its interest rate policy. Finally, it is convenient at this point to find the value enjoyed by the household from the marginal job in firm $i$. Writing $n_{t}=\int_{0}^{1} n_{i t} d i$, I differentiate the household's Bellman equation with respect to $n_{i t}$, subject again to (1) and (2), obtaining

$$
H_{n_{i}}\left(n_{t}, B_{t-1}\right) \equiv H_{n_{i}, t}=u^{\prime}\left(c_{t}\right) \frac{W_{i t}}{P_{t}}-v\left(h_{t}\right)-b-p\left(\theta_{t}\right) \beta E_{t} H_{n, t+1}+(1-\lambda) \beta E_{t} H_{n_{i}, t+1},
$$

where $E_{t} H_{n, t+1}=E_{t} \int_{0}^{1} \frac{v_{i t}}{v_{t}} H_{n_{i}, t+1} d i$ is the expected average marginal value in period $t+1$ and $\frac{v_{i t}}{v_{t}}$ is the probability of being matched to firm $i$. Therefore, the value that the household enjoys from holding a job in firm $i$ consists of the real wage (in terms of marginal utility) net of labor disutility, plus the future value of the job conditional on survival, $(1-\lambda) \beta E_{t} H_{n_{i}, t+1}$, minus the value the individual would contribute to the household if she searched for a job, $p\left(\theta_{t}\right) \beta E_{t} H_{n, t+1}$.

\footnotetext{
${ }^{15}$ Notice that all Bellman equations in this paper depend also on the aggregate state of the economy. For clarity of exposition, I will omit this dependence.
} 


\section{$2.2 \quad$ Firms}

I assume the existence of two types of firms: producers and retailers. Producers use capital and labor to produce a homogenous intermediate good; hiring in this sector is subject to search frictions. Retailers buy the intermediate good from producers, transform it into differentiated consumption goods and sell them for a price chosen at random intervals. The two-sector assumption allows me to separate the hiring and pricing decisions of firms, which is convenient for the following reason. In a context of staggered price-setting, merging the hiring and pricing decisions would create sources of strategic complementarity in price-setting analogous to those analyzed by Woodford (2005) in his treatment of firm-specific capital investment. However, considering such complementarities would blur the exposition of the policy tradeoffs created by search frictions and nominal rigidities, and would not affect the main qualitative results of the paper.

\subsubsection{Producers}

A measure-one continuum of producers produce a homogenous intermediate good and sell it to retailers at the perfectly competitive real price $\varphi_{t}$. Each firm $i$ hires capital $k_{i t}$ in a competitive market with rental price $r_{t}$. The firm also employs

$n_{i t}$ workers. Each worker provides $h_{i t}$ hours of work and receives a real wage $\frac{W_{i t}}{P_{t}}$. These inputs are transformed into output by means of a constant returns to scale technology, $y_{i t}=A_{t} f\left(n_{i t} h_{i t}, k_{i t}\right)$. $A_{t}$ is an aggregate productivity shock, the log of which follows an autoregressive process, $\ln A_{t} \equiv a_{t}=\rho_{a} a_{t-1}+\varepsilon_{t}^{a}$, where $\varepsilon_{t}^{a}$ is an iid shock. For simplicity, I assume that $A_{t}$ is the only source of aggregate uncertainty in the model. However, the main qualitative results of the paper would be unaltered if I introduced other types of real disturbances, such as preference shocks or shocks to government expenditure.

In every period, each firm loses a fraction $\lambda$ of its workers. To replace them, it posts a number $v_{i t}$ of vacancies. The cost of posting vacancies, in units of the intermediate good, is given by the following hiring cost function,

$$
h c_{i t}=\frac{\chi}{1+\psi}\left(\frac{v_{i t}}{n_{i t}}\right)^{1+\psi} n_{i t} .
$$

Therefore, $\psi$ measures the degree of convexity of hiring costs. By taking $\psi$ to 0 , we can recover the linear specification of the standard search and matching model. However, the case where $\psi>0$ is empirically more plausible: using US corporate sector data, Merz and Yashiv (2004) find support for the convex specification in a structural estimation of the search and matching model. 
Assuming that firms in this sector are sufficiently large, the fraction of vacancies they fill in each period with certainty is given by the matching rate for vacancies, $q\left(\theta_{t}\right)$. New workers do not become productive until the next period. ${ }^{16}$ Therefore, employment in firm $i$ is given by the following law of motion,

$$
n_{i t+1}=(1-\lambda) n_{i t}+q\left(\theta_{t}\right) v_{i t}
$$

Each producer solves the following problem,

$$
J\left(n_{i t}\right)=\max _{k_{i t}, v_{i t}}\left\{\varphi_{t}\left[A_{t} f\left(n_{i t} h_{i t}, k_{i t}\right)-h c_{i t}\right]-r_{t} k_{i t}-\frac{W_{i t}}{P_{t}} n_{i t}+E_{t} \beta_{t, t+1} J\left(n_{i t+1}\right)\right\},
$$

subject to (4) and (5). The term $\beta_{t, t+s} \equiv \beta^{s} \frac{u^{\prime}\left(c_{t+s}\right)}{u^{\prime}\left(c_{t}\right)}$ is the stochastic discount factor by which households value time- $(t+s)$ state-contingent real payoffs. The first order condition with respect to $k_{i t}$ equalizes the marginal revenue product of capital to its rental rate, $\varphi_{t} A_{t} f_{2}\left(n_{i t} h_{i t}, k_{i t}\right)=r_{t}$. Given constant returns to scale in production, it follows that the capital-labor ratio $\frac{k_{i t}}{n_{i t} h_{i t}}$ is equalized across firms. This implies that the marginal product of labor, $m p l_{i t} \equiv A_{t} f_{1}\left(n_{i t} h_{i t}, k_{i t}\right)$, is also equalized. Constant returns to scale also implies that the production function can be written as $m p l_{t} n_{i t} h_{i t}+m p k_{t} k_{i t}$, where $m p l_{t}$ and $m p k_{t}$ denote the common values of the marginal product of labor and capital, respectively. Using this and the first order condition for capital, I can write

$$
J\left(n_{i t}\right)=\max _{v_{i t}}\left\{\varphi_{t}\left[m p l_{t} n_{i t} h_{i t}-h c_{i t}\right]-\frac{W_{i t}}{P_{t}} n_{i t}+E_{t} \beta_{t, t+1} J\left(n_{i t+1}\right)\right\},
$$

subject again to (4) and (5). The first order condition with respect to vacancies is given by

$$
\varphi_{t} \chi z_{i t}^{\psi}=q\left(\theta_{t}\right) E_{t} \beta_{t, t+1} J_{n}\left(n_{i t+1}\right),
$$

where $z_{i t} \equiv \frac{v_{i t}}{n_{i t}}$ is the vacancy rate. The value of the marginal worker for the firm is given by

$$
J_{n}\left(n_{i t}\right)=\varphi_{t}\left[m p l_{t} h_{i t}+\psi \frac{\chi}{1+\psi} z_{i t}^{1+\psi}\right]-\frac{W_{i t}}{P_{t}}+(1-\lambda) E_{t} \beta_{t, t+1} J_{n}\left(n_{i t+1}\right),
$$

i.e. the worker's marginal revenue product, plus saving on hiring costs from having one more worker, minus the real wage plus the job's continuation value. Combining

\footnotetext{
${ }^{16}$ This represents the time involved in finding and training new workers.
} 
(6) and (7), I can write the firm's hiring decision as,

$$
\frac{\varphi_{t} \chi z_{i t}^{\psi}}{q\left(\theta_{t}\right)}=E_{t} \beta_{t, t+1}\left\{\varphi_{t+1}\left[m p l_{t+1} h_{i t+1}+\psi \frac{\chi}{1+\psi} z_{i t+1}^{1+\psi}\right]-\frac{W_{i t+1}}{P_{t+1}}+(1-\lambda) \frac{\varphi_{t+1} \chi z_{i t+1}^{\psi}}{q\left(\theta_{t+1}\right)}\right\} .
$$

Hours per worker, $h_{i t}$, are determined by firm and worker in a privately efficient way, i.e. so as to maximize the joint surplus of their employment relationship. The joint surplus is the sum of the firm's surplus, equation (7), and the worker's surplus in terms of the consumption basket, equation (3) divided by $u^{\prime}\left(c_{t}\right)$. The first order condition is given by

$$
\varphi_{t} m p l_{t}=\frac{v^{\prime}\left(h_{i t}\right)}{u^{\prime}\left(c_{t}\right)}
$$

i.e. the marginal revenue product of labor is equal to the marginal disutility of work measured in units of consumption. Because the marginal revenue product is the same for all producers, equation (9) implies that hours are equalized across producers, $h_{i t}=h_{t}$ for all $i$.

\subsubsection{Retailers}

There is a measure-one continuum of monopolistic retailers, each of them producing one differentiated consumption good. Due to imperfect substitutability across individual goods, each retailer faces the following demand curve for its product,

$$
c_{j t}^{d}=\left(\frac{P_{j t}}{P_{t}}\right)^{-\gamma} c_{t}
$$

Producing $c_{j t}^{d}$ units of good $j$ requires the same amount of the intermediate input, which is purchased from producers at the real price $\varphi_{t}$. Therefore, $\varphi_{t}$ represents the real marginal cost of production for retailers. I follow the Calvo (1983) model of price setting: each period a randomly chosen fraction $\delta_{p}$ of firms fail to reset their price. Therefore, when a firm has the chance of changing its price, it solves

$$
\max _{P_{j t}} E_{t} \sum_{s=0}^{\infty} \delta_{p}^{s} \beta_{t, t+s}\left(\frac{P_{j t}}{P_{t+s}}-\varphi_{t+s}\right) c_{j t+s}^{d}
$$

subject to (10). The optimal pricing decision is given by

$$
E_{t} \sum_{s=0}^{\infty} \delta_{p}^{s} \beta_{t, t+s}\left(\frac{P_{t}^{*}}{P_{t+s}}-\mu \varphi_{t+s}\right) P_{t+s}^{\gamma} c_{t+s}=0
$$


where $P_{t}^{*}$ is the common price chosen by all price-setters. Therefore, each pricesetting firm chooses a nominal price such that, for the expected duration of the price contract, its relative price equals a constant mark-up $\mu \equiv \frac{\gamma}{\gamma-1}>1$ over real marginal costs on average. Since price-setters are randomly chosen, the law of motion for the price level is given by

$$
P_{t}^{1-\gamma}=\delta_{p} P_{t-1}^{1-\gamma}+\left(1-\delta_{p}\right)\left(P_{t}^{*}\right)^{1-\gamma}
$$

\subsubsection{Equilibrium in the intermediate good market}

Given constant returns to scale in production, I can express aggregate output as

$$
\begin{aligned}
\int_{0}^{1} A_{t} f\left(n_{i t} h_{t}, k_{i t}\right) d i & =\int_{0}^{1} A_{t} n_{i t} h_{t} f\left(1, \tilde{k}_{t}\right) d i=A_{t} n_{t} h_{t} f\left(1, \tilde{k}_{t}\right) \\
& =A_{t} f\left(n_{t} h_{t}, n_{t} h_{t} \tilde{k}_{t}\right)=A_{t} f\left(n_{t} h_{t}, \bar{k}\right),
\end{aligned}
$$

where $\tilde{k}_{t}$ is the common capital-labor ratio and in the last equality I have used the market clearing condition for capital, $\int k_{i t} d i=\int n_{i t} h_{t} \tilde{k}_{t} d i=n_{t} h_{t} \tilde{k}_{t}=\bar{k}$. In equilibrium, total supply of the intermediate good net of hiring costs, $A_{t} f\left(n_{t} h_{t}, \bar{k}\right)-$ $\int h c_{i t} d i$, must equal total demand by retailers, $\int c_{j t}^{d} d j$. Using (4) and (10), this condition can be written as

$$
A_{t} f\left(n_{t} h_{t}, \bar{k}\right)=\int_{0}^{1} \frac{\chi}{1+\psi}\left(\frac{v_{i t}}{n_{i t}}\right)^{1+\psi} n_{i t} d i+c_{t} \Delta_{t}
$$

where $\Delta_{t} \equiv \int_{0}^{1}\left(\frac{P_{j t}}{P_{t}}\right)^{-\gamma} d j$ is a measure of price dispersion.

\section{The efficient equilibrium}

Before analyzing wage determination in the decentralized economy, it is convenient to find the efficient allocation, since it will be the benchmark relative to which monetary policy outcomes will be evaluated. I assume that the search frictions in the labor market are a technological constraint on the social planner, just like the production function. Therefore, I want to characterize the constrained-efficient equilibrium of this economy. The social planner's optimization problem is thus the following,

$$
V\left(n_{t}\right)=\max _{c_{t}, h_{t}, v_{t}, n_{t+1}}\left\{u\left(c_{t}\right)-n_{t}\left[v\left(h_{t}\right)+b\right]+\beta E_{t} V\left(n_{t+1}\right)\right\}
$$


subject to the law of motion of employment,

$$
n_{t+1}=(1-\lambda) n_{t}+m\left(v_{t}, 1-n_{t}\right),
$$

and the aggregate resource constraint. Since the social planner avoids any inefficient dispersion in relative prices, the price dispersion term $\Delta_{t}$ in (13) becomes 1 . The same holds for vacancy rates. Therefore, the relevant resource constraint is given by

$$
A_{t} f\left(n_{t} h_{t}, \bar{k}\right)=\frac{\chi}{1+\psi}\left(\frac{v_{t}}{n_{t}}\right)^{1+\psi} n_{t}+c_{t} .
$$

Using the two constraints to substitute for $c_{t}$ and $n_{t+1}$ in the Bellman equation, the social planner is left with the choice of hours per worker, $h_{t}$, and vacancies, $v_{t}$. The first order condition with respect to hours is given by

$$
m p l_{t}=\frac{v^{\prime}\left(h_{t}\right)}{u^{\prime}\left(c_{t}\right)}
$$

where $m p l_{t}=A_{t} f_{1}\left(n_{t} h_{t}, \bar{k}\right)$ is the marginal product of labor. Therefore, the social planner equalizes the marginal product of labor and the marginal rate of substitution between consumption and leisure.

The first order condition with respect to vacancies is given by

$$
\chi z_{t}^{\psi} u^{\prime}\left(c_{t}\right)=m_{1}\left(v_{t}, u_{t}\right) \beta E_{t} V_{n}\left(n_{t+1}\right) .
$$

That is, the social planner equalizes the social marginal cost and the social marginal benefit of matching workers to firms. The social value of the marginal worker is given by

$V_{n}\left(n_{t}\right)=u^{\prime}\left(c_{t}\right)\left[m p l_{t} h_{t}+\psi \frac{\chi}{1+\psi} z_{t}^{1+\psi}\right]-v\left(h_{t}\right)-b+\left[1-\lambda-m_{2}\left(v_{t}, u_{t}\right)\right] \beta E_{t} V_{n}\left(n_{t+1}\right)$.

Assuming that the matching function has constant elasticities $\epsilon$ and $1-\epsilon$, respectively, I can write $m_{1}\left(v_{t}, u_{t}\right)=\epsilon q\left(\theta_{t}\right)$ and $m_{2}\left(v_{t}, u_{t}\right)=(1-\epsilon) p\left(\theta_{t}\right) \cdot{ }^{17}$ Combining this with equations (15) and (16), I obtain

$$
\frac{\chi z_{t}^{\psi}}{q\left(\theta_{t}\right)}=E_{t} \beta_{t, t+1}\left\{\begin{array}{c}
\epsilon\left[m p l_{t+1} h_{t+1}+\psi \frac{\chi}{1+\psi} z_{t+1}^{1+\psi}-\frac{v\left(h_{t+1}\right)+b}{u^{\prime}\left(c_{t+1}\right)}\right] \\
+\left[1-\lambda-(1-\epsilon) p\left(\theta_{t+1}\right)\right] \frac{\chi z_{t+1}^{\psi}}{q\left(\theta_{t+1}\right)}
\end{array}\right\} .
$$

Equation (17) is the condition for socially efficient job creation in this economy.

\footnotetext{
${ }^{17}$ This is indeed the case if I assume a Cobb-Douglas specification, as I do later on.
} 


\section{Equilibrium with flexible (Nash) wages}

Following most of the search and matching literature, I assume that, when firms reset nominal wages, they do so according to the Nash bargaining solution. That is, firm and worker each receive a constant fraction of the match surplus. Letting $S_{i t}^{f} \equiv J_{n}\left(n_{i t}\right)$ denote the firm surplus, I can write $(7)$ as

$$
S_{i t}^{f}=\bar{w}_{i t}-\frac{W_{i t}}{P_{t}}+(1-\lambda) E_{t} \beta_{t, t+1} S_{i t+1}^{f},
$$

where

$$
\bar{w}_{i t} \equiv \varphi_{t}\left[m p l_{t} h_{t}+\psi \frac{\chi}{1+\psi} z_{i t}^{1+\psi}\right] .
$$

We can interpret $\bar{w}_{i t}$ as a limiting real wage that, if paid in every period, would make the firm surplus equal to 0. Similarly, letting $S_{i t}^{w} \equiv \frac{H_{n_{i}, t}}{u^{\prime}\left(c_{t}\right)}$ denote the worker surplus expressed in terms of the consumption basket, I can express (3) as

$$
S_{i t}^{w}=\frac{W_{i t}}{P_{t}}-\underline{w}_{t}+(1-\lambda) E_{t} \beta_{t, t+1} S_{i t+1}^{w}
$$

where

$$
\underline{w}_{t} \equiv \frac{v\left(h_{t}\right)+b}{u^{\prime}\left(c_{t}\right)}+p\left(\theta_{t}\right) E_{t} \beta_{t, t+1} S_{t+1}^{w}
$$

and $S_{t+1}^{w}$ is the average worker surplus across firms. $\bar{w}_{i t}$ is therefore a limiting real wage that would make the worker surplus equal to 0 if it was paid in every period.

Let $\varepsilon \in(0,1)$ denote the firm's bargaining power. Nash bargaining implies that the firm receives a fraction $\varepsilon$ of match surplus, $S_{i t}^{f}+S_{i t}^{w}$, that is,

$$
(1-\varepsilon) S_{i t}^{f}=\varepsilon S_{i t}^{w}
$$

Combining (18), (20) and (22), the resulting real wage is just the weighted average of the two limiting wages,

$$
\frac{W_{i t}}{P_{t}}=(1-\varepsilon) \bar{w}_{i t}+\varepsilon \underline{w}_{t} \equiv w_{i t}^{n a s h} .
$$

If all wages are changed in every period, then all producers behave in exactly the same way and I can drop the subscript $i$. On the other hand, using (22) and the first order condition for vacancies, equation (6), I can write $E_{t} \beta_{t, t+1} S_{t+1}^{w}=\frac{1-\varepsilon}{\varepsilon} E_{t} \beta_{t, t+1} S_{t+1}^{f}=$ 
$\frac{1-\varepsilon}{\varepsilon} \frac{\varphi_{t} \chi z_{t}^{\psi}}{q\left(\theta_{t}\right)}$. This, together with the definitions of the limiting wages and the fact that $p\left(\theta_{t}\right)=\theta_{t} q\left(\theta_{t}\right)$, allows me to write the real wage as

$$
\frac{W_{t}}{P_{t}}=(1-\varepsilon) \varphi_{t}\left[m p l_{t} h_{t}+\psi \frac{\chi}{1+\psi} z_{t}^{1+\psi}+\chi z_{t}^{\psi} \theta_{t}\right]+\varepsilon \frac{v\left(h_{t}\right)+b}{u^{\prime}\left(c_{t}\right)}
$$

Using (24) to substitute for the real wage in (8), I obtain

$$
\varphi_{t} \frac{\chi z_{t}^{\psi}}{q\left(\theta_{t}\right)}=E_{t} \beta_{t, t+1}\left\{\begin{array}{c}
\varepsilon\left[\varphi_{t+1}\left(m p l_{t+1} h_{t+1}+\psi \frac{\chi}{1+\psi} z_{t+1}^{1+\psi}\right)-\frac{v\left(h_{t+1}\right)+b}{u^{\prime}\left(c_{t+1}\right)}\right] \\
+\left[1-\lambda-(1-\varepsilon) p\left(\theta_{t+1}\right)\right] \varphi_{t+1} \frac{\chi z_{t+1}^{\psi}}{q\left(\theta_{t+1}\right)}
\end{array}\right\} .
$$

Notice that period-by-period Nash bargaining per se does not guarantee that the central bank can achieve the first-best allocation, which requires equations (14) and (17) to hold, as well as the absence of price dispersion $\left(\Delta_{t}=1\right)$. First, by equation (12), avoiding price dispersion requires keeping the price level constant. By equation (11), this requires the central bank to ensure that the marginal cost equals the inverse of the retailer gross mark-up in every period: $\varphi_{t}=\mu^{-1}<1$. But then, by equation (9), hours per worker are inefficiently low. In principle, the mark-up could be eliminated by assuming that retailer sales are subsidized at the rate $s$, such that the effective mark-up is given by $\mu_{s} \equiv \frac{\mu}{1+s}$, and then setting $s=\mu-1$, such that $\mu_{s}=1 .^{18}$

However, even if the retailer mark-up is eliminated, imposing $\varphi_{t}=\varphi_{t+1}=1$ in equation (25) is efficient only if the firm's share of the match surplus, $\varepsilon$, is equal to the elasticity of the matching function with respect to vacancies, $\epsilon$. In this case, firms internalize the congestions that they create in the labor market in a way that leads them to post the efficient number of vacancies. This is the well-known Hosios condition for efficient job creation (Hosios, 1990). Notice that the zero net mark-up and the Hosios condition ensure that the steady state of this economy is efficient. ${ }^{19}$ The central bank can then replicate the social planner allocation by choosing the level of aggregate consumption $c_{t}$ consistent with $\varphi_{t}=1$ in equation (9). If $\mu_{s}=1$, this also ensures that the price level is kept constant. To summarize ${ }^{20}$

Proposition 1 If wages are Nash-bargained in every period, the central bank can achieve the efficient allocation if and only if the economy's steady state is efficient. In this case, the efficient allocation is achieved by keeping the price level constant.

\footnotetext{
${ }^{18}$ See e.g. Rotemberg and Woodford (1997).

${ }^{19}$ Cyclical fluctuations will generally be inefficient as a result of nominal rigidities.

${ }^{20}$ The same result as the one in Proposition 1 has been found in independent work by Blanchard and Gali (2006) in a similar framework.
} 


\section{$5 \quad$ Equilibrium with staggered wages}

Period-by-period renegotiation of wages is a convenient theoretical benchmark, but is not empirically appealing. In reality, nominal wages remain unchanged for many periods, and most wages are not changed more often than once a year (see e.g. Gottschalk, 2004). In addition, there is plenty of evidence that wage changes across firms are not synchronized, at least for the majority of industrialized economies. ${ }^{21}$ In order to formalize the staggered nature of nominal wage adjustment, I assume that in every period a randomly chosen fraction $\delta_{w}$ of firms do not renegotiate wages with their employees, in analogy with the Calvo model of price-setting. ${ }^{22}$ Therefore, $\delta_{w}$ is the probability that a firm's nominal wage does not change in the following period. I assume that workers hired in between contracting periods receive the same wage as continuing workers. As found by Bewley's (1999) survey of business managers and labor leaders in the US, equity considerations at the firm level often lead the wages of new hires to be linked to the existing internal pay structure. Bewley observes that this is especially true for the primary sector of the labor market, i.e. jobs that are long-term and full-time, which is precisely the kind of employment relationships considered in this model.

Let the superscript $*(0)$ denote firms who do (do not) renegotiate, and let $W_{i t}^{*}$ be the agreed-upon nominal wage. For renegotiating firms, the match surplus can be expressed as

$$
S_{i t}^{f *}=\bar{w}_{i t}-\frac{W_{i t}^{*}}{P_{t}}+(1-\lambda) E_{t} \beta_{t, t+1}\left[\delta_{w} S_{i t+1}^{f 0}+\left(1-\delta_{w}\right) S_{i t+1}^{f *}\right] .
$$

The expression for $S_{i t}^{f 0}$ is the same, except for $W_{i t}^{*}$ being replaced by some nominal wage agreed in the past. Using this, I can express the firm surplus as

$$
\begin{aligned}
S_{i t}^{f *}= & E_{t} \sum_{s=0}^{\infty} \beta_{t, t+s}(1-\lambda)^{s} \delta_{w}^{s}\left(\bar{w}_{i t+s}-\frac{W_{i t}^{*}}{P_{t+s}}\right) \\
& +(1-\lambda)\left(1-\delta_{w}\right) E_{t} \sum_{s=0}^{\infty} \beta_{t, t+1+s}(1-\lambda)^{s} \delta_{w}^{s} S_{i t+s+1}^{f *} .
\end{aligned}
$$

\footnotetext{
${ }^{21}$ See Taylor (1999) and the references therein.

${ }^{22}$ Staggered wage bargaining a la Calvo has been first introduced by Gertler and Trigari (2006), in a model that abstracts from nominal variables.
} 
Similarly, the worker surplus can be expressed as

$$
\begin{aligned}
S_{i t}^{w *}= & \frac{W_{i t}^{*}}{P_{t}}-\underline{w}_{i t}+(1-\lambda) E_{t} \beta_{t, t+1}\left[\delta_{w} S_{i t+1}^{w 0}+\left(1-\delta_{w}\right) S_{i t+1}^{w *}\right] \\
= & E_{t} \sum_{s=0}^{\infty} \beta_{t, t+s}(1-\lambda)^{s} \delta_{w}^{s}\left(\frac{W_{i t}^{*}}{P_{t+s}}-\underline{w}_{i t+s}\right) \\
& +(1-\lambda)\left(1-\delta_{w}\right) E_{t} \sum_{s=0}^{\infty} \beta_{t, t+1+s}(1-\lambda)^{s} \delta_{w}^{s} S_{i t+s+1}^{w *} .
\end{aligned}
$$

In firms that do renegotiate, the Nash bargaining rule applies,

$$
(1-\varepsilon) S_{i t}^{f *}=\varepsilon S_{i t}^{w *} .
$$

Since equation (28) holds in all states in which the wage is renegotiated, the $S_{i t+s+1}^{f *}$ and $S_{i t+s+1}^{w *}$ terms in the expressions for firm and worker surplus cancel out. I thus obtain the following expression for the nominal wage agreement,

$$
E_{t} \sum_{s=0}^{\infty} \beta_{t, t+s}(1-\lambda)^{s} \delta_{w}^{s}\left(\frac{W_{i t}^{*}}{P_{t+s}}-w_{i t+s}^{n a s h}\right)=0,
$$

where $w_{i t}^{\text {nash }}$ is given by equation (23). In a context of staggered wage bargaining, $w_{i t}^{\text {nash }}$ must be interpreted as the real wage that would obtain if wages were Nash bargained in every period, i.e. if wages were perfectly flexible. For brevity, I will refer to $w_{i t}^{\text {nash }}$ as the Nash wage in firm $i$. Therefore, according to equation (29) the nominal wage agreed by both parties is such that, for the expected duration of the wage contract, the real wage equals the Nash wage on average. Notice the analogy with the pricing decision, equation (11): the same way that the marginal cost constitutes the target price for multiperiod price contracts, the Nash wage represents the target wage when firm and worker agree on a multiperiod wage contract.

From equation (8), the only source of heterogeneity in vacancy rates, $z_{i t}$, is next period's real wages, $\frac{W_{i t+1}}{P_{t+1}}$ (remember that, by equation 9 , hours are equalized across firms). I now guess that all renegotiating firms strike the same agreement, $W_{i t}^{*}=W_{t}^{*}$. Since $W_{t}^{*}$ remains in place in those future states in which it is not renegotiated, if follows from (23) and (19) that the expected value of every $w_{i t+s}^{\text {nash }}$ in (29) is the same for all renegotiating firms, which verifies my guess. Since renegotiating firms are randomly chosen, the average nominal wage across firms evolves according to the following law of motion,

$$
\int_{0}^{1} W_{i t} d i \equiv W_{t}=\delta_{w} W_{t-1}+\left(1-\delta_{w}\right) W_{t}^{*}
$$




\section{Linear-quadratic analysis}

In the rest of the paper, I will follow the linear-quadratic (LQ) approach to monetary policy analysis pioneered by Rotemberg and Woodford (1997) and extensively applied in Woodford (2003, Ch. 6). This requires obtaining a second order approximation of the representative households' welfare criterion, as well as a first order approximation of the equilibrium conditions. As is well-known, this method has several advantages. First, the quadratic welfare criterion clarifies what the stabilization objectives of the central bank are. Second, a first-order approximation of the equilibrium conditions is enough to evaluate the welfare effects of alternative policies with a degree of accuracy of up to second order. Finally, this linear representation of the monetary transmission mechanism makes it easier to understand what are the trade-offs for monetary policy.

\subsection{The model in log-linear form}

From now onwards, I assume the following functional forms for preferences over consumption and leisure, as well as the production and matching technologies,

$$
\begin{gathered}
u\left(c_{t}\right)=\frac{c_{t}^{1-\sigma^{-1}}}{1-\sigma^{-1}}, \\
v\left(h_{t}\right)=\frac{h_{t}^{1+\eta}}{1+\eta}, \\
A_{t} f\left(n_{t} h_{t}, \bar{k}\right)=A_{t}\left(n_{t} h_{t}\right)^{\alpha} \bar{k}^{1-\alpha}, \\
m\left(v_{t}, u_{t}\right)=v_{t}^{\epsilon} u_{t}^{1-\epsilon},
\end{gathered}
$$

Therefore, $\sigma$ is the intertemporal elasticity of substitution, and $\eta$ is the inverse of the Frisch elasticity of labor supply.

For any variable $e_{i t}$, let $\hat{e}_{i t} \equiv \log \left(e_{i t} / e\right)$ denote the log-deviation from its steady state value, $e$. I start the approximation by log-linearizing the firm's job creation condition, equation (8). I then rescale it by $\frac{y}{n}$ to obtain

$$
\begin{gathered}
(1+\psi) \frac{s_{v}}{\lambda}\left[\hat{\varphi}_{t}+(1-\epsilon) \hat{\theta}_{t}+\psi \hat{z}_{i t}-E_{t} \hat{\beta}_{t, t+1}\right]= \\
\beta E_{t}\left\{\alpha \widehat{m p l}_{t+1}+\hat{h}_{t+1}\right)+\psi s_{v}(1+\psi) \hat{z}_{i t+1}+\left(\alpha+\psi s_{v}\right) \hat{\varphi}_{t+1}-s_{w} \hat{w}_{i t+1} \\
\left.+(1-\lambda)(1+\psi) \frac{s_{v}}{\lambda}\left[\hat{\varphi}_{t+1}+(1-\epsilon) \hat{\theta}_{t+1}+\psi \hat{z}_{i t+1}\right]\right\}
\end{gathered}
$$


where $s_{v} \equiv \frac{h c}{y}$ is total hiring costs as a fraction of GDP and $s_{w} \equiv \frac{n w}{y}$ is the labor share of GDP, both in the steady state. ${ }^{23}$ In order to aggregate the individual job creation condition, I make use of the following result, ${ }^{24}$

Lemma 1 The vacancy rate of any firm $i$ admits the following log-linear approximation,

$$
\hat{z}_{i t}=\hat{z}_{t}-\tau_{z}\left(\log W_{i t}-\log W_{t}\right)
$$

where $\hat{z}_{t} \equiv \int_{0}^{1} \hat{z}_{i t} d i$ and

$$
\tau_{z}=\frac{\beta \delta_{w} s_{w}}{\left(1-\beta \delta_{w}\right)(1+\psi) \frac{s_{v}}{\lambda} \psi} .
$$

That is, relative vacancy rates are a negative function of relative wages. Intuitively, since the current nominal wage is kept constant in the following period with some probability, firms with a higher current nominal wage expect a lower surplus from new matches and therefore post fewer vacancies.

As shown in the proof of Lemma 1, this result allows me to obtain the following aggregate job creation equation,

$$
\begin{gathered}
(1+\psi) \frac{s_{v}}{\lambda}\left[\hat{\varphi}_{t}+(1-\epsilon) \hat{\theta}_{t}+\psi \hat{z}_{t}-E_{t} \hat{\beta}_{t, t+1}\right]= \\
\beta E_{t}\left\{\alpha \widehat{m p l}_{t+1}+\hat{h}_{t+1}\right)+\psi \frac{s_{v}}{\lambda}(1+\psi) \hat{z}_{t+1}+\left(\alpha+\psi s_{v}\right) \hat{\varphi}_{t+1}-s_{w} \hat{w}_{t+1} \\
\left.+(1-\lambda)(1+\psi) \frac{s_{v}}{\lambda}\left[\hat{\varphi}_{t+1}+(1-\epsilon) \hat{\theta}_{t+1}\right]\right\} .
\end{gathered}
$$

From $\theta_{t}=\frac{v_{t}}{u_{t}}$ and $u_{t}=1-n_{t}$, I can write, respectively,

$$
\begin{gathered}
\hat{\theta}_{t}=\hat{v}_{t}-\hat{u}_{t}, \\
\hat{u}_{t}=-\frac{n}{u} \hat{n}_{t} .
\end{gathered}
$$

Letting $z_{t} \equiv \int \frac{n_{i t}}{n_{t}} z_{i t} d i=\frac{v_{t}}{n_{t}}$ denote the average vacancy rate, I have

$$
\hat{z}_{t}=\hat{v}_{t}-\hat{n}_{t}
$$

The stochastic discount factor is given by $\hat{\beta}_{t, t+1}=\sigma^{-1}\left(\hat{c}_{t}-\hat{c}_{t+1}\right)$. The log-linear approximation of the Beveridge curve, equation (1), is given by

$$
\hat{n}_{t+1}=(1-\lambda-p) \hat{n}_{t}+\lambda \epsilon \hat{\theta}_{t}
$$

\footnotetext{
${ }^{23}$ In the derivation of (31) I have also used the Beveridge curve in the steady state, $\frac{1}{q(\theta)}=\frac{v}{\lambda n}$, where $q(\theta) v$ is the total number of matches, as well as $m p l=\alpha \frac{y}{n h}$.

${ }^{24}$ The proof of all Lemmas is in Appendix A.
} 
where $p \equiv p(\theta)$ and I have used the fact that, in the steady state, $\frac{p u}{n}=\lambda$. Aggregate consumption $\hat{c}_{t}$ is controlled by the central bank by means of its interest rate policy. Therefore, $\hat{c}_{t}$ will be determined by the monetary policy rule. The marginal product of labor is given by

$$
\widehat{m p l}_{t}=a_{t}-(1-\alpha)\left(\hat{n}_{t}+\hat{h}_{t}\right) .
$$

Log-linearization of the hours decision and the aggregate resource constraint, equations (9) and (13) respectively, yields

$$
\begin{gathered}
\hat{\varphi}_{t}=\eta \hat{h}_{t}+\sigma^{-1} \hat{c}_{t}-\widehat{m p l}_{t}, \\
a_{t}+\alpha\left(\hat{n}_{t}+\hat{h}_{t}\right)=s_{c} \hat{c}_{t}+s_{v}\left[(1+\psi) \hat{z}_{t}+\hat{n}_{t}\right],
\end{gathered}
$$

where $s_{c} \equiv \frac{c}{y}=1-s_{v}$ is the consumption share of GDP in the steady state, and in equation (36) I have used the fact that the price dispersion term $\hat{\Delta}_{t}$ is actually a second order term. ${ }^{25}$

By definition, real wage inflation is equal to nominal wage inflation minus price inflation,

$$
\hat{w}_{t}=\hat{w}_{t-1}+\pi_{w t}-\pi_{t},
$$

where $\pi_{w t} \equiv \log \left(W_{t} / W_{t-1}\right)$ and $\pi_{t} \equiv \log \left(P_{t} / P_{t-1}\right)$. Log-linearizing equations (11) and (12) and combining them, I obtain the familiar New-Keynesian Phillips curve ${ }^{26}$

$$
\pi_{t}=\kappa_{p} \hat{\varphi}_{t}+\beta E_{t} \pi_{t+1}
$$

where

$$
\kappa_{p} \equiv \frac{\left(1-\beta \delta_{p}\right)\left(1-\delta_{p}\right)}{\delta_{p}} .
$$

Therefore, real marginal costs are the only driving force of inflation.

Solving for wage inflation deserves more attention. I start by log-linearizing the nominal wage agreement, equation (29),

$$
E_{t} \sum_{s=0}^{\infty} \beta^{s}(1-\lambda)^{s} \delta_{w}^{s}\left(\log W_{i t}^{*}-\log P_{t+s}-\log w-\hat{w}_{i t+s}^{\text {nash }}\right)=0,
$$

where the firm's period- $t$ Nash wage is given by

$$
\begin{aligned}
s_{w} \hat{w}_{i t}^{\text {nash }}= & (1-\varepsilon)\left[\alpha\left(\widehat{m p l}_{t}+\hat{h}_{t}\right)+\psi s_{v}(1+\psi) \hat{z}_{i t}+\left(\alpha+\psi s_{v}\right) \hat{\varphi}_{t}\right] \\
& +\varepsilon\left[\alpha\left(\hat{h}_{t}+\frac{1+\tilde{b}}{1+\eta} \sigma^{-1} \hat{c}_{t}\right)+p \beta S_{y}^{w}\left[\epsilon \hat{\theta}_{t}+E_{t}\left(\hat{\beta}_{t, t+1}+\hat{S}_{t+1}^{w}\right)\right]\right] .
\end{aligned}
$$

\footnotetext{
${ }^{25}$ See Appendix B.

${ }^{26}$ The derivation of equation (38) is fairly standard. See e.g. Walsh (2003, section 5.4).
} 
$S_{y}^{w} \equiv \frac{n S^{w}}{y}$ is total worker surplus over GDP in the steady state and $\tilde{b} \equiv \frac{b}{v(h)}$ is fixed work disutility over steady-state variable work disutility. Notice that all terms in (40) except for $\hat{z}_{i t}$ are common to all firms. Let $\hat{w}_{t}^{n a s h} \equiv \int_{0}^{1} \hat{w}_{i t}^{n a s h} d i$ be the average Nash wage. For a firm that has not changed its nominal wage since period $t$, I can write

$$
\begin{aligned}
s_{w} \hat{w}_{i t+s}^{n a s h} & =s_{w} \hat{w}_{t+s}^{n a s h}+(1-\varepsilon) \psi s_{v}(1+\psi)\left(\hat{z}_{i t+s}-\hat{z}_{t+s}\right) \\
& =s_{w} \hat{w}_{t+s}^{n a s h}-(1-\varepsilon) \psi s_{v}(1+\psi) \tau_{z}\left(\log W_{i t}^{*}-\log W_{t+s}\right)
\end{aligned}
$$

where in the second equality I have used Lemma 1. From here, it is relatively straightforward to derive the following result,

Lemma 2 Nominal wage inflation is given by

$$
\pi_{w t}=\kappa_{w}\left(\hat{w}_{t}^{n a s h}-\hat{w}_{t}\right)+\beta_{\lambda} E_{t} \pi_{w t+1},
$$

where

$$
\begin{aligned}
\kappa_{w} & \equiv \frac{\left(1-\beta_{\lambda} \delta_{w}\right)\left(1-\delta_{w}\right)}{\delta_{w}} \frac{1}{1+\phi} \\
\phi & \equiv s_{w}^{-1}(1-\varepsilon) \psi s_{v}(1+\psi) \tau_{z}
\end{aligned}
$$

and $\beta_{\lambda} \equiv(1-\lambda) \beta$.

Therefore, the gap between the actual and the Nash average real wage is the driving force of wage inflation in this model. The reason is the following. The Nash wage is the target wage for multiperiod wage contracts. To the extent that actual real wages are e.g. below their target, renegotiating firms will increase their nominal wages, with the resulting positive wage inflation. ${ }^{27}$

Notice that the slope of equation (42) is analogous to that of the price inflation equation (38), with two differences. First, the discount factor $\beta_{\lambda}$ in $\kappa_{w}$ takes into account the fact that the job match survives in the following period with probability $(1-\lambda)$, thus shortening the horizon of the bargaining parties. Second, $\kappa_{w}$ is reduced by the presence of $\phi$. This parameter represents an index of real rigidity in the sense of Ball and Romer (1990), and it has the effect of slowing the adjustment of nominal wages. To see why, assume that the average Nash wage is expected to increase. A renegotiating firm will then increase its nominal wage by a certain amount. This

${ }^{27}$ The Erceg et al. (2000) model produces a wage inflation equation similar to (42), with the gap between the marginal rate of substitution between consumption and leisure and the average real wage as the driving force. This is because in their model, the marginal rate of substitution is the target for multiperiod nominal wage contracts. 
will lead to an increase in its relative wage, and by Lemma 1 to a fall in its relative vacancy rate. But then its own Nash (target) wage will fall relative to the average, which will lead the firm to undo some of the increase in its nominal wage. That is, renegotiating firms adjust their wages by less than they would in the absence of real rigidity. This effect is absent in the case of prices, because the target price (i.e. the marginal cost) does not depend on one's own pricing decision. ${ }^{28}$

It only remains to derive the average Nash wage. I now make use of the following result,

Lemma 3 The worker surplus and the firm surplus, respectively, admit the following log-linear approximation,

$$
\begin{gathered}
\hat{S}_{i t}^{w}=\hat{S}_{t}^{w}+\tau_{w}\left(\log W_{i t}-\log W_{t}\right), \\
\hat{S}_{i t}^{f}=\hat{S}_{t}^{f}-\tau_{f}\left(\log W_{i t}-\log W_{t}\right),
\end{gathered}
$$

where $\hat{S}_{t}^{w} \equiv \int_{0}^{1} \hat{S}_{i t}^{w} d i, \hat{S}_{t}^{f} \equiv \int_{0}^{1} \hat{S}_{i t}^{f} d i$ and

$$
\begin{aligned}
& \tau_{w}=\frac{s_{w}}{\left[1-(1-\lambda) \beta \delta_{w}\right] S_{y}^{w}}, \\
& \tau_{f}=\frac{s_{w}+\psi s_{v}(1+\psi) \tau_{z}}{\left[1-(1-\lambda) \beta \delta_{w}\right] S_{y}^{f}},
\end{aligned}
$$

where $S_{y}^{w} \equiv \frac{n S^{w}}{y}$ and $S_{y}^{f} \equiv \frac{n S^{f}}{y}$.

That is, the surplus enjoyed by workers in firm $i$ relative to the average is increasing in that firm's relative wage. The opposite is true for the relative surplus enjoyed by the firm. With Lemma 3 in hand, it is possible to obtain the following expression for the average Nash wage,

Lemma 4 The average Nash wage is given by

$$
\begin{aligned}
s_{w} \hat{w}_{t}^{n a s h}= & (1-\varepsilon)\left[\alpha \widehat{m p l}_{t}+\psi s_{v}(1+\psi) \hat{z}_{t}+\left(\alpha+\psi s_{v}\right) \hat{\varphi}_{t}\right]+\alpha \hat{h}_{t} \\
& +\varepsilon \alpha \frac{1+\tilde{b}}{1+\eta} \sigma^{-1} \hat{c}_{t}+(1-\varepsilon) p(1+\psi) \frac{s_{v}}{\lambda}\left(\hat{\theta}_{t}+\hat{\varphi}_{t}+\psi \hat{z}_{t}-\tau E_{t} \pi_{w t+1}\right),
\end{aligned}
$$

where $\tau \equiv\left(\tau_{w}+\tau_{f}\right) \frac{\delta_{w}}{1-\delta_{w}}$.

\footnotetext{
${ }^{28}$ The absence of real rigidity in price setting is due to my two-sector assumption and to retailers' linear production technology. This is not the case in the standard one-sector New Keynesian model with decreasing returns in production, see e.g. Woodford (2003, section 3.1).
} 
Notice that log-linearization of the Nash wage in the flexible-wage case, equation (24), would yield the same expression as (43), except for the presence of $E_{t} \pi_{w t+1}$. With staggered wages, expected wage inflation reduces the average Nash wage. To see this, I log-linearize equation (30) in period $t+1$,

$$
\log W_{t+1}^{*}-\log W_{t+1}=\frac{\delta_{w}}{1-\delta_{w}}\left(\log W_{t+1}-\log W_{t}\right),
$$

When wage inflation is positive, both sides of the equation are positive. A job seeker that is matched to a non-renegotiating firm receives on average a negative relative wage (since $\log W_{t}<\log W_{t+1}$ ) and, from Lemma 3, enjoys a negative relative surplus. If she is matched to a renegotiating firm, from (28) I have $\hat{S}_{t+1}^{w *}=\hat{S}_{t+1}^{f *}$; but from $\log W_{t+1}^{*}>\log W_{t+1}$ and Lemma $3, \hat{S}_{t+1}^{f *}$ is then lower than the average firm surplus. Either way, wage inflation reduces the expected average surplus for job seekers, relative to the expected average firm surplus (given by $\hat{\theta}_{t}+\hat{\varphi}_{t}+\psi \hat{z}_{t}$ in equation 43). This reduces the outside option for workers and therefore the Nash wage.

\subsection{The quadratic welfare criterion}

The second step of the LQ method consists of deriving a second order approximation of the welfare criterion, which will be the objective function in the central bank's optimal monetary policy problem. At this point, I assume that the steady state of this economy is efficient. As seen in section 4, this requires making the following two assumptions.

Assumption 1 Retailer sales are subsidized at the rate $s=\mu-1$.

Assumption 2 The Hosios condition is satisfied: $\varepsilon=\epsilon$.

The reason for assuming an efficient steady state is that the linear terms in the second order approximation of the welfare criterion disappear, because their coefficients are zero. As shown by Benigno and Woodford (2005a, 2005b), when the steady state is not efficient, it is necessary to perform second order approximations of the equilibrium conditions in order to substitute for the linear terms in the welfare criterion. This is cumbersome even in the most standard New Keynesian model (see Benigno and Woodford, 2005a). In order to simplify the analysis, I will constrain it to the case of an efficient steady state. 
I now obtain the following second order approximation of the welfare criterion, ${ }^{29}$

$$
\sum_{t=0}^{\infty} \beta^{t}\left\{u\left(c_{t}\right)-n_{t}\left[v\left(h_{t}\right)+b\right]\right\}=-\Omega \sum_{t=0}^{\infty} \beta^{t} L_{t}+t . i . p .+O^{3},
$$

where $\Omega \equiv \frac{u^{\prime}(c) y}{2}>0, t . i . p$. represents terms independent of policy as of date $0, O^{k}$ are terms of order $k$-th and higher in the size of the exogenous shock, and $L_{t}$ is a purely quadratic loss function given by

$$
L_{t} \equiv \lambda_{p} \pi_{t}^{2}+\lambda_{w} \pi_{w t}^{2}+L_{t}^{n, h}
$$

where $\lambda_{p} \equiv s_{c} \frac{\gamma}{\kappa_{p}}, \lambda_{w} \equiv(1+\psi) s_{v} \tau_{z}^{2} \frac{\psi}{\kappa_{w}} \frac{1-\beta_{\lambda} \delta_{w}}{1-\beta \delta_{w}}$ and

$L_{t}^{n, h} \equiv s_{c} \sigma^{-1} \hat{c}_{t}^{2}+\alpha\left[\left(\hat{n}_{t}+\hat{h}_{t}\right)^{2}+\eta \hat{h}_{t}^{2}\right]-\left[a_{t}+\alpha\left(\hat{n}_{t}+\hat{h}_{t}\right)\right]^{2}+(1+\psi) s_{v}\left[(1-\epsilon) \hat{\theta}_{t}^{2}+\psi \hat{z}_{t}^{2}\right]$.

Equation (45) illustrates the central bank's stabilization objectives. First, when price setting is staggered, inflation causes price dispersion. From the aggregate resource constraint, equation (13), price dispersion $\Delta_{t}$ increases the amount of resources needed produce a certain amount of the consumption basket, $c_{t}$. As a result, inflation causes a welfare loss. Second, under staggered wage bargaining, wage inflation causes wage dispersion. From Lemma 1, wage dispersion creates dispersion in hiring rates. ${ }^{30}$ Since hiring costs are convex in hiring rates, from equation (13) dispersion in hiring rates increases the amount of resources used in vacancy posting. Therefore, wage inflation too reduces welfare.

The term $L_{t}^{n, h}$ measures the success of monetary policy in stabilizing (un)employment and hours around their efficient paths. Indeed, the expected present discounted sum of $L_{t}^{n, h}$ is exactly the second order approximation of the social planner's objective function. To see this, I minimize

$$
E_{0} \sum_{t=0}^{\infty} \beta^{t}\left\{\begin{array}{c}
s_{c} \sigma^{-1} \hat{c}_{t}^{2}+\alpha\left[\left(\hat{n}_{t}+\hat{h}_{t}\right)^{2}+\eta \hat{h}_{t}^{2}\right]-\left[a_{t}+\alpha\left(\hat{n}_{t}+\hat{h}_{t}\right)\right]^{2} \\
+(1+\psi) s_{v}\left[(1-\epsilon)\left(\hat{v}_{t}+\frac{n}{u} \hat{n}_{t}\right)^{2}+\psi\left(\hat{v}_{t}-\hat{n}_{t}\right)^{2}\right]
\end{array}\right\}
$$

with respect to $\hat{c}_{t}, \hat{h}_{t}, \hat{v}_{t}$ and $\hat{n}_{t}$, subject to the log-linear approximations of the Beveridge curve (equation 33 with $\hat{v}_{t}+\frac{n}{u} \hat{n}_{t}$ replacing $\hat{\theta}_{t}$ ) and the aggregate resource

\footnotetext{
${ }^{29}$ The proof is in Appendix B.

${ }^{30}$ Strictly speaking, a firm's hiring rate is given by $q\left(\theta_{t}\right) \frac{v_{i t}}{n_{i t}}$, i.e. the product of the matching rate for vacancies and the vacancy rate. However, since the former is the same for all firms, dispersion in vacancy rates is equivalent to dispersion in hiring rates. From now onwards, I treat both concepts as synonyms.
} 
constraint (equation 36 with $\hat{v}_{t}-\hat{n}_{t}$ replacing $\hat{z}_{t}$ ). These are the two constraints on the social planner problem. Let $\phi_{t}^{n}$ and $\phi_{t}^{c}$ be the Lagrange multipliers on (33) and (36), respectively. The first order conditions are given by

$$
\begin{aligned}
& \phi_{t}^{c}=\sigma^{-1} \hat{c}_{t}, \\
& \widehat{m p l}_{t}=\eta \hat{h}_{t}+\phi_{t}^{c} \\
& (1+\psi) \frac{s_{v}}{\lambda}\left[(1-\epsilon) \hat{\theta}_{t}+\psi \hat{z}_{t}-\phi_{t}^{c}\right]=\beta \epsilon E_{t} \phi_{t+1}^{n}, \\
& \phi_{t}^{n}=\alpha \widehat{\operatorname{mpl}}_{t}+\psi(1+\psi) s_{v} \hat{z}_{t}-\left(\alpha+\psi s_{v}\right) \phi_{t}^{c}-(1+\psi) \frac{s_{v}}{\lambda} p(1-\epsilon) \hat{\theta}_{t} \\
& +[1-\lambda-(1-\epsilon) p] E_{t} \phi_{t+1}^{n},
\end{aligned}
$$

where $\widehat{m p l}_{t}$ is given by (34). Combining the first two conditions, I have

$$
\widehat{m p l}_{t}=\eta \hat{h}_{t}+\sigma^{-1} \hat{c}_{t},
$$

which is exactly the log-linear approximation of the social planner's hours decision, equation (14). Combining the last two conditions, I have ${ }^{31}$

$$
\begin{gathered}
(1+\psi) \frac{s_{v}}{\lambda}\left[(1-\epsilon) \hat{\theta}_{t}+\psi \hat{z}_{t}-E_{t} \hat{\beta}_{t, t+1}\right] \\
=\beta E_{t}\left\{\epsilon\left[\alpha \widehat{\alpha m p l}_{t+1}+\psi s_{v}(1+\psi) \hat{z}_{t+1}-\alpha \frac{1+\tilde{b}}{1+\eta} \sigma^{-1} \hat{c}_{t+1}\right]\right. \\
\left.+[1-\lambda-(1-\epsilon) p](1+\psi) \frac{s_{v}}{\lambda} \psi \hat{z}_{t+1}+(1-\lambda-p)(1+\psi) \frac{s_{v}}{\lambda}(1-\epsilon) \hat{\theta}_{t+1}\right\},
\end{gathered}
$$

which is exactly the log-linear approximation of the efficient job creation condition, equation (17). This should be no surprise: since the objective function is purely quadratic, the first order conditions of the linear-quadratic problem are the same as the log-linearized first order conditions of the exact problem.

It follows from the preceding analysis that (46) attains its minimum (though not zero) value in the social planner allocation. In the decentralized economy, the presence of price and wage stickiness will distort hours and hiring decisions. This will create inefficient variation in the terms in (46), and therefore a greater welfare loss.

\footnotetext{
${ }^{31}$ In order to form the $\hat{\beta}_{t, t+1}$ term in the left hand side of (48), I am using equation (17) in the steady state, rescaled by $\frac{y}{n}$,

$$
(1+\psi) \frac{s_{v}}{\lambda}\{1-\beta[1-\lambda-(1-\epsilon) p]\}=\beta \epsilon\left(\frac{\eta-\tilde{b}}{1+\eta} \alpha+\psi s_{v}\right) .
$$
}




\subsection{Policy trade-offs}

It is now possible to illustrate easily the trade-offs that the central bank faces. Assume that, consistent with the case for price stability, the central bank sets $\pi_{t}=0$ in every period. By equation (38), this requires stabilizing the marginal cost, $\hat{\varphi}_{t}=0$. From equation (35), the hours decision would be given exactly by the social planner's hours decision, equation (47). This does not imply however that hours follow their efficient path: any distortion in aggregate hiring results in distortion in aggregate consumption $\hat{c}_{t}$ (through the resource constraint, equation 36), and therefore in $\hat{h}_{t}$. As I will show, aggregate hiring is distorted when $\pi_{t}=0$. However, if hiring costs are small as a fraction of GDP (as I assume later on), this distortion is not quantitatively important.

The zero inflation policy exacerbates other, more important distortions. The failure of some nominal wages to adjust creates a gap between the actual and the Nash average real wage. To see this, I can combine (37) and (42) and impose $\pi_{t}=0$ to express the average real wage as a weighted average of its own lag, its expected lead and the Nash wage,

$$
\hat{w}_{t}=\rho_{b} \hat{w}_{t-1}+\left(1-\rho_{b}-\rho_{f}\right) \hat{w}_{t}^{n a s h}+\rho_{f} E_{t} \hat{w}_{t+1},
$$

where

$$
\begin{array}{r}
\rho_{b} \equiv \frac{\delta_{w}}{\delta_{w}+\delta_{w} \kappa_{w}+\delta_{w} \beta_{\lambda}}, \\
\rho_{f} \equiv \frac{\delta_{w} \beta_{\lambda}}{\delta_{w}+\delta_{w} \kappa_{w}+\delta_{w} \beta_{\lambda}},
\end{array}
$$

and $\lim _{\delta_{w} \rightarrow 0} \delta_{w} \kappa_{w}=1$. Therefore, the only way that $\hat{w}_{t}$ equals $\hat{w}_{t}^{n a s h}$ is if $\delta_{w}=0$, i.e. if nominal wages are flexible. If $\delta_{w}>0$, real wages will lag behind Nash wages and from (42) wage inflation will be non-zero. Following e.g. a negative productivity shock, Nash wages fall on impact. Since Nash wages are the target for multiperiod wage contracts, nominal wages in renegotiating firms will fall. This results in wage deflation and thus in inefficient wage dispersion. Therefore, staggered wages induce a trade-off between price and wage inflation. This trade-off is also present in Erceg et al. (2000), but in a framework that is subject to Barro's critique.

On the other hand, I can express the real wage as $\hat{w}_{t}=\hat{w}_{t}^{\text {nash }}+\left(\hat{w}_{t}-\hat{w}_{t}^{n a s h}\right)$. Inserting this in (32), using (43) to substitute for $s_{w} \hat{w}_{t+1}^{n a s h}$ and imposing $\varepsilon=\epsilon$ and 
$\hat{\varphi}_{t}=\hat{\varphi}_{t+1}=0$, I can represent the job creation equation under inflation targeting as

$$
\begin{gathered}
(1+\psi) \frac{s_{v}}{\lambda}\left[(1-\epsilon) \hat{\theta}_{t}+\psi \hat{z}_{t}-E_{t} \hat{\beta}_{t, t+1}\right] \\
=\beta E_{t}\left\{\epsilon\left[\alpha \widehat{m p l}_{t+1}+\psi s_{v}(1+\psi) \hat{z}_{t+1}-\alpha \frac{1+\tilde{b}}{1+\eta} \sigma^{-1} \hat{c}_{t+1}\right]\right. \\
+[1-\lambda-(1-\epsilon) p](1+\psi) \frac{s_{v}}{\lambda} \psi \hat{z}_{t+1}+(1-\lambda-p)(1+\psi) \frac{s_{v}}{\lambda}(1-\epsilon) \hat{\theta}_{t+1} \\
\left.-s_{w}\left(\hat{w}_{t+1}-\hat{w}_{t+1}^{\text {nash }}\right)+(1-\epsilon) p(1+\psi) \frac{s_{v}}{\lambda} \tau \pi_{w t+2}\right\} .
\end{gathered}
$$

This is the same as the social-planner's job creation condition, equation (48), except for the two terms in the last line. That is, job creation under the zero inflation policy is inefficient. Following e.g. a negative productivity shock that reduces Nash wages on impact, the failure of some nominal wages to fall leads the expected average real wage to be too high relative to its Nash counterpart. This amplifies the negative effect of the shock on the profitability of posting vacancies. On the other hand, renegotiating firms will reduce their nominal wages in order to bring real wages closer to their target; this will create expectations of future deflation, which from Lemma 4 increases the average Nash wage and further reduces the incentives to hire. Therefore, both effects work towards raising unemployment above its efficient path. It follows that there is also a trade-off between inflation and unemployment stabilization.

The tension among goals is resolved as follows. Continuing with the example of a negative shock, the central bank should allow for a temporary increase in inflation. This way, by equation (37) it can accelerate the convergence of real wages towards their Nash counterparts. Since actual wages are then closer to their targets, renegotiating firms will cut their nominal wages by less, thus reducing wage dispersion. Also, the smaller expected gap in wages and the smaller expected wage deflation reduce the negative effect of the shock on the profitability of posting vacancies, thus bringing unemployment closer to its efficient path.

Quantifying the magnitude of these trade-offs and the optimal policy response to shocks is the purpose of section 6.5. Before turning to this and the calibration of the model, it is now worth to consider the nature of optimal monetary policy in two limiting cases: flexible wages and flexible prices.

\subsubsection{Flexible wages}

If nominal wages are fully flexible, $\delta_{w}=0$, then the weight on wage inflation in the loss function, $\lambda_{w}$, disappears, such that wage inflation is not a concern for the central 
bank anymore. Equation (42) becomes $\hat{w}_{t}=\hat{w}_{t}^{\text {nash }}$. The central bank can then set $\hat{\varphi}_{t}=0$ and thus eliminate price inflation. On the other hand, job creation would be given by (49), with $\hat{w}_{t+1}-\hat{w}_{t+1}^{\text {nash }}=0$ and $\tau=0$; this would yield exactly equation (48), which is the social planner's job creation decision. Since $\hat{\varphi}_{t}=0$ and there is no distortion in vacancy posting, hours too are at their efficient level. Therefore, the monetary authority would be able to replicate the first-best allocation. This is just a restatement of Proposition 1, which claims the same result for the model in exact form.

\subsubsection{Flexible prices}

If prices are fully flexible, $\delta_{p}=0$, then $\lambda_{p}$ in the loss function becomes 0 and inflation has no welfare consequences. Furthermore, all retailers set price equal to marginal cost, which implies $\varphi_{t}=1$, or $\hat{\varphi}_{t}=0$. The central bank can then ensure that $\hat{w}_{t}=\hat{w}_{t}^{\text {nash }}$ holds at all times by adjusting price inflation in (37) accordingly. ${ }^{32}$ From (42), wage inflation and thus wage dispersion are eliminated. Using (43) to substitute for $\hat{w}_{t+1}=\hat{w}_{t+1}^{\text {nash }}$ in (32) and imposing $\pi_{w t+2}=0$, the job creation equation is exactly the same as its social planner counterpart, equation (48). Therefore, when prices are flexible, the monetary authority is also able to replicate the first-best equilibrium.

\subsection{Calibration}

In what follows, I assume a monthly frequency for the model. On the one hand, as emphasized by Gertler and Trigari (2006), a monthly calibration is better able to capture the high rate of job finding in the US. Second, and more importantly, the committees of the world's major central banks hold meetings every month in order to make their interest rate decisions. ${ }^{33}$ Inflation data and forecasts, on which policy decisions are largely based, have a monthly frequency too.

As in most of the business cycle literature, I set the intertemporal elasticity of substitution $\sigma$ to 1 , a value which is consistent with balanced growth in the neoclassical growth model. Regarding the Frisch elasticity of labor supply $\eta^{-1}$, there is traditionally a conflict between the low values estimated in the micro empirical literature (up to 0.5; see e.g. Card 1994) and the values higher than unity used in the macro literature on the basis of balanced growth considerations (see e.g. Cooley and

\footnotetext{
${ }^{32}$ In the flexible price case, it is still possible for the central bank to control the price level through the consumption Euler equation. See Woodford (2003, Ch. 2) for more details.

${ }^{33}$ This is the case for the Bank of England, the European Central Bank and the Bank of Japan. The US Federal Reserve holds eight regularly scheduled meetings every year, but more meetings are held when needed.
} 
Prescott, 1995). Therefore, I choose a compromise value of 1 . The discount factor $\beta$ is set to $0.99^{\frac{1}{3}}$. The autocorrelation of the productivity shock is set to $\rho_{a}=0.95^{\frac{1}{3}}$.

For the matching function, I set $\epsilon$ equal to 0.6, following the US evidence in Blanchard and Diamond (1989). As in Gertler and Trigari (2006), I use a monthly separation rate of $\lambda=0.035$, in order to match the evidence that jobs last for two years and a half. Shimer (2005) calculates a monthly job-finding rate of 0.276 for the US; I thus set $p=0.30$. From the Beveridge curve, this implies a steady-state unemployment rate of $u=\lambda /(p+\lambda)=0.10$, which is reasonable if we allow the model unemployment rate to include those individuals registered as inactive that are actively searching for jobs. ${ }^{34}$. The employment rate is thus $1-n=0.90$. Following the evidence in Merz and Yashiv (2004), the degree of convexity of hiring costs is set to $\psi=2$.

Following most of the search and matching literature, I set $s_{v}=0.01{ }^{35}$ I now consider the Nash wage, equation (24), in the steady state and rescale it by $\frac{y}{n}$ to obtain

$$
s_{w}=(1-\epsilon)\left[\alpha+\psi s_{v}+(1+\psi) s_{v} \frac{n}{u}\right]+\epsilon \frac{1+\tilde{b}}{1+\eta} \alpha,
$$

On the other hand, equation (17) in the steady state can be rescaled by $\frac{y}{n}$ to obtain

$$
(1+\psi) \frac{s_{v}}{\lambda}\{1-\beta[1-\lambda-(1-\epsilon) p]\}=\beta \epsilon\left[\frac{\eta-\tilde{b}}{1+\eta} \alpha+\psi s_{v}\right] .
$$

Assuming a labor share of GDP of $s_{w}=2 / 3$, I can use (50) and (51) to solve for $\alpha$ and $\tilde{b}$, obtaining values of 0.68 and 0.39 , respectively.

Regarding the New Keynesian side of the model, I assume an elasticity of substitution across goods $\gamma$ of 7.67, which in the absence of the sales subsidy would imply that retailers charge a mark-up of $15 \%$ over marginal costs. Klenow and Kryvtsov (2005) find that $26 \%$ of prices are changed every month in the US; therefore I choose $\delta_{p}=1-0.25=0.75$. This implies an elasticity of inflation with respect to marginal costs of $\kappa_{p}=0.084$. The latter implies a weight on inflation stabilization of $\lambda_{p}=90.18$.

Most wages in the US are renegotiated once a year (see e.g. Gottschalk, 2004). This suggests an average wage duration of $\frac{1}{1-\delta_{w}}=12$ months, or $\delta_{w}=0.92$. The resulting degree of strategic complementarity in wage bargaining, $\phi=0.15$, turns out to be quite small. The slope of the wage inflation equation is then given by

\footnotetext{
${ }^{34}$ The evidence shows that flows from inactivity to employment account for a large fraction of total flows to employment in the US, see e.g. Blanchard and Diamond (1989).

${ }^{35}$ See e.g. Andolfatto (1996) and Gertler and Trigari (2006).
} 
$\kappa_{w}=0.0094$. The elasticity of vacancy rates with respect to relative wages is $\tau_{z}=$ 4.11. These values imply a weight on wage inflation of $\lambda_{w}=129.18$. Once we rescale all the weights in the loss function by their sum, price and wage inflation receive weights of 57 and 41 per cent, respectively, for a total of 98 per cent. See Table 1 for a summary of parameter values.

Table 1. Parameter values

\begin{tabular}{cc|cc|cc|cc}
\hline \hline$\lambda$ & 0.035 & $\epsilon$ & 0.6 & $\gamma$ & 7.67 & $\tau_{z}$ & 4.11 \\
$p$ & 0.30 & $\eta$ & 1 & $\delta_{p}$ & 0.75 & $\lambda_{p}$ & 90.18 \\
$\psi$ & 2 & $\sigma$ & 1 & $\delta_{w}$ & 0.92 & $\lambda_{w}$ & 129.2 \\
$\rho_{a}$ & 0.983 & $\tilde{b}$ & 0.39 & $\kappa_{p}$ & 0.084 & $\beta$ & 0.997 \\
$\alpha$ & 0.68 & $s_{w}$ & 0.67 & $\kappa_{w}$ & 0.0094 & $s_{v}$ & 0.01
\end{tabular}

\subsection{Simulation}

\subsubsection{Zero inflation policy}

I start the quantitative analysis by simulating the behavior of the decentralized economy when the central bank pursues a policy of full inflation stabilization, $\pi_{t}=$ $0 .^{36}$ Panels (a) and (b) of Figure 1 plot the economy's response to a 1 per cent negative productivity shock. ${ }^{37}$ The fall in the marginal product of jobs reduces the Nash wage on impact. Given that the Nash wage is the target in wage negotiations, nominal wages in renegotiating firms fall accordingly. This results in wage deflation.

On the other hand, the fall in productivity reduces the profitability of posting vacancies and therefore job creation. As a result, unemployment increases. The fall in job creation is amplified by the stickiness of nominal wages, which further reduces the value of posting vacancies. To see this, I compute the response of the social planner economy to the same shock. As seen in Figure 2, unemployment increases too in the first-best allocation, albeit by less than under the zero inflation policy. This can also be seen in Figure 3, where the dotted solid line represents the unemployment response under the zero inflation policy net of the same response in the efficient allocation. ${ }^{3839}$

\footnotetext{
${ }^{36}$ The log-linear model is solved using Uhlig's (1999) undetermined coefficients method.

${ }^{37}$ Price and wage inflation responses are expressed as annualized rates, i.e. $12 \pi_{t}$ and $12 \pi_{w t}$.

${ }^{38}$ Notice that the net responses in Figure 3 become negative after 23 and 33 months, respectively. The reason is that, even though unemployment responds less in the social planner allocation, it also returns to its steady state level more slowly than under the two policies considered.

${ }^{39}$ The response of hours per worker is very weak, with a peak at $0.08 \%$, and a maximum absolute deviation from its efficient path of $0.06 \%$, which confirms my previous claim that this distortion is quantitatively negligible.
} 
Therefore, targeting zero inflation generates inefficient outcomes in unemployment and wage inflation. Since the central bank also cares about the latter two objectives (especially wage inflation, which receives a 57 per cent weight in the loss function under the chosen calibration), it will find it optimal to strike a balance among the three objectives.

\subsubsection{Optimal policy commitment}

At time 0, the central bank chooses the state-contingent plan that minimizes

$$
E_{0} \sum_{t=0}^{\infty} \beta^{t}\left\{\begin{array}{c}
\lambda_{p} \pi_{t}^{2}+\lambda_{w} \pi_{w t}^{2}+s_{c} \sigma^{-1} \hat{c}_{t}^{2}+\alpha\left[\left(\hat{n}_{t}+\hat{h}_{t}\right)^{2}+\eta \hat{h}_{t}^{2}\right] \\
-\left[a_{t}+\alpha\left(\hat{n}_{t}+\hat{h}_{t}\right)\right]^{2}+(1+\psi) s_{v}\left[(1-\epsilon) \hat{\theta}_{t}^{2}+\psi \hat{z}_{t}^{2}\right]
\end{array}\right\},
$$

subject to the job creation condition (equation 32), the Beveridge curve (33), the marginal product of labor (34) and marginal cost (35) equations, the resource constraint (36), the real wage equation (37), the Phillips curve (38), the wage inflation (42) and Nash wage (43) equations, as well as $\hat{\beta}_{t, t+1}=\sigma^{-1}\left(\hat{c}_{t}-\hat{c}_{t+1}\right), \hat{\theta}_{t}=\hat{v}_{t}+\frac{n}{u} \hat{n}_{t}$ and $\hat{z}_{t}=\hat{v}_{t}-\hat{n}_{t}$.

Panels (c) and (d) of Figure 1 show the economy's response to a 1 per cent negative productivity shock, under the optimal monetary policy commitment. The distortions created by staggered wage bargaining are reflected in the failure of actual wages to track their flexible-wage (Nash) counterparts. Relative to the situation under inflation targeting, the central bank can improve matters by creating a certain amount of inflation and thus accelerating the convergence of real wages towards their Nash counterparts. This can be seen by comparing panels (b) and (d): whereas such convergence takes 40 months under the zero inflation policy, it takes only 25 months under the optimal policy. This allows the central bank to reduce wage deflation and the subsequent dispersion in hiring rates. The smaller gap in wages and the smaller expected wage deflation also reduce the negative effect of the shock on the profitability of posting vacancies. As a result, vacancies fall by less, and unemployment increases by less, than under the zero inflation policy. This can also be seen in Figure 3, where unemployment (net of its efficient path) is less volatile than under inflation targeting. ${ }^{40}$

\footnotetext{
${ }^{40}$ The hours response is again very weak, with a peak at $0.06 \%$, and a maximum absolute deviation from its efficient path of $0.05 \%$.
} 


\subsubsection{Welfare loss from inflation targeting}

The suboptimality of the zero inflation policy depends on the frequency of nominal wage adjustment. Indeed, the weight on wage inflation in the loss function, $\lambda_{w}$, is an increasing and convex function of $\delta_{w}$ : first, the less synchronization there is in nominal wage changes, the greater the wage dispersion caused by wage inflation; second, since $\tau_{z}$ is an increasing function of $\delta_{w}$, from Lemma 1 wage dispersion will induce a greater dispersion in hiring rates and thus a greater welfare loss. In addition, greater stickiness of nominal wages means a bigger gap between the actual and the Nash average real wage and therefore greater distortions in job creation.

Figure 4 plots the value of

$$
E\left(L_{t}\right)-E\left(L_{t}^{s p}\right)
$$

as a function of the mean duration of nominal wage contracts $\left(\frac{1}{1-\delta_{w}}\right) . L_{t}$ is the loss function given by (45) and $E\left(L_{t}^{s p}\right)$ is the value of $E\left(L_{t}\right)$ in the social planner allocation (i.e. its minimum possible value). ${ }^{41} \quad$ The solid and dotted solid lines represent the net expected welfare loss under the optimal and the zero inflation policy, respectively. If nominal wages are completely flexible (i.e. if contracts last for $\frac{1}{1-0}=1$ month on average), from Proposition 1 the optimal policy is precisely the zero inflation policy, and the welfare loss is the same as in the social planner economy. For moderate contract durations, inflation targeting is still a very good approximation to the optimal policy. However, as wage contracts become longer, the distortions caused by wage dispersion and inefficient job creation become very large, and the central bank's failure to adjust real wages by using inflation starts taking its toll on welfare. Thus, whereas net expected welfare losses under the zero inflation policy are just $10 \%$ higher than under the optimal policy for mean contract durations of 6 months, they are $45 \%$ higher when contracts last for 9 months, and $106 \%$ higher under the 12-month wage contracts assumed in the baseline calibration.

Since price and wage inflation receive most of the weight in the loss function, I also consider policy rules that stabilize a properly chosen weighted average of price and wage inflation. That is, among the following family of rules,

$$
\xi \pi_{w t}+(1-\xi) \pi_{t}=0
$$

the weight $\xi \in[0,1]$ is chosen so as to minimize the unconditional expectation of equation (45). The dashed line in Figure 4 represents the net expected welfare loss

\footnotetext{
${ }^{41}$ The figure assumes a standard deviation for the shock to productivity, $\varepsilon_{t}^{a}$, of $0.7 \%$. However, since the productivity shock is the only source of aggregate uncertainty in this model, the relative welfare losses under alternative policies do not depend on the volatility of the shock.
} 
under this rule, again as a function of mean contract duration. This policy therefore is nearly optimal for any contract length. For the baseline of 12-month contracts, the optimal weight is given by $\xi=59.3 \%$ (i.e. slightly more than the relative weight on wage inflation stabilization), and the net expected loss under this policy is only $4.8 \%$ higher than under the optimal commitment.

\subsubsection{The bargaining set}

As claimed in the introduction, this framework is free of Barro's (1977) critique, because preset nominal wages do not distort existing employment relationships. Hours per employee are independent of wages, because they are chosen so as to maximize the joint match surplus. Regarding the continuation of existing jobs, the failure of some nominal wages to adjust must not lead to the break-up of otherwise efficient employment relationships, in the form of either quits or firings. That is, in every firm (renegotiating or not) both employer and employees must always enjoy a nonnegative surplus: $S_{i t}^{f}, S_{i t}^{w} \geq 0, \forall i, t$. From equations (18) and (20), this means that the real wage, $w_{i t}$, must always lie inside the bargaining set, i.e. the set of wages above the worker's reservation wage and below the firm's reservation wage,

$$
w_{i t} \in\left[\bar{w}_{i t}+(1-\lambda) E_{t} \beta_{t, t+1} S_{i t+1}^{f}, \underline{w}_{t}-(1-\lambda) E_{t} \beta_{t, t+1} S_{i t+1}^{w}\right] .
$$

In the flexible-wage case, the Nash wage is just the weighted average of the two bounds of the bargaining set (the continuation values would cancel out as a result of the bargaining rule, producing expression 23); therefore, actual wages are always inside the bargaining set. However, when renegotiations are infrequent, it is only in renegotiating firms that the wage equals the weighted average of both reservation wages; in all other firms, it is not guaranteed that wages lie inside the bargaining set. With large enough shocks and in firms with sufficiently old nominal wages, the latter are bound to fall outside the bargaining set. This section shows that, for shocks of empirically plausible size, the vast majority of wages remain inside the bargaining set.

The fraction of firms that last changed their wage $k$ periods ago is given by $\left(1-\delta_{w}\right) \delta_{w}^{k}$. Following Gertler and Trigari (2006), I calculate the minimum value of $\tilde{k}$

such that the fraction of firms with wages older than $\tilde{k}$ periods, $1-\sum_{k=0}^{\tilde{k}}\left(1-\delta_{w}\right) \delta_{w}^{k}$, is less than 1 per cent. For my baseline of 12 -month wage contracts $\left(\delta_{w}=\frac{12-1}{12}\right), \tilde{k}$ is equal to 52 months.

Up to a log-linear approximation, a firm's surplus is proportional to $1+\hat{S}_{i t}^{f}$. Using Lemma 3, it follows that the firm's surplus is positive if and only if

$$
\log W_{i t}<\log W_{t}+\tau_{f}^{-1}\left(1+\hat{S}_{t}^{f}\right) \equiv \log R_{t}^{f}
$$


where $R_{t}^{f}$ is the firm's reservation wage in nominal terms. Log-linearizing the expression for the firm surplus, equation (26) for any $i$, and using Lemma 1 to average across firms, I can express the average firm surplus (rescaled by $\frac{y}{n}$ ) as

$S_{y}^{f} \hat{S}_{t}^{f}=\alpha\left(\widehat{m p l}_{t}+\hat{h}_{t}\right)+\psi s_{v}(1+\psi) \hat{z}_{t}+\left(\alpha+\psi s_{v}\right) \hat{\varphi}_{t}-s_{w} \hat{w}_{t}+(1-\lambda) \beta S_{y}^{f} E_{t}\left(\hat{\beta}_{t, t+1}+\hat{S}_{t+1}^{f}\right)$.

Similarly, from Lemma 3 the worker surplus is positive up to a log-linear approximation if and only if

$$
\log W_{i t}>\log W_{t}-\tau_{w}^{-1}\left(1+\hat{S}_{t}^{w}\right) \equiv \log R_{t}^{w}
$$

where $R_{t}^{f}$ is the worker's reservation wage in nominal terms. Log-linearizing the worker surplus, equation (27) for any $i$, and aggregating across firms yields the following expression for the average worker surplus,

$S_{y}^{w} \hat{S}_{t}^{w}=s_{w} \hat{w}_{t}-\alpha\left(\hat{h}_{t}+\frac{1+\tilde{b}}{1+\eta} \sigma^{-1} \hat{c}_{t}\right)-p \beta S_{y}^{w} \epsilon \hat{\theta}_{t}+(1-\lambda-p) \beta S_{y}^{w} E_{t}\left(\hat{\beta}_{t, t+1}+\hat{S}_{t+1}^{w}\right)$.

In firms that last negotiated 52 months ago, the nominal wage equals $\log W_{t-52}^{*}$. I therefore require that $\log W_{t-52}^{*}$ is between $\log R_{t}^{f}$ and $\log R_{t}^{w}$ at all times,

$$
\log R_{t}^{w} \leq \log W_{t-52}^{*} \leq \log R_{t}^{f}
$$

In order to check that this condition holds for a reasonably large sample size, I simulate 1,000 observations of the model economy, under both the zero inflation and the optimal policy. I assume that the shock to exogenous productivity, $\varepsilon_{t}^{a}$, is normally distributed with mean zero and a standard deviation of $0.7 \%$ (see Prescott, 1986). The upper panels of Figures 5 and 6 show the reservation wages as well as $\log W_{t-52}^{*}$ (all deflated by the price level, $\log P_{t}$ ) for the optimal and the zero inflation policy, respectively. In both cases, the actual wage never falls outside the bargaining set. Therefore, I can conclude that, at least for $99 \%$ of all firms, Barro's critique is avoided.

It is also interesting to analyze how firm and worker surplus in this group of firms behave in response to shocks. From Lemma 3, in firms that last negotiated 52 months ago, the firm and worker surplus are given, respectively, by

$$
\begin{aligned}
& \hat{S}_{t}^{f}-\tau_{f}\left(\log W_{t-52}^{*}-\log W_{t}\right), \\
& \hat{S}_{t}^{w}+\tau_{w}\left(\log W_{t-52}^{*}-\log W_{t}\right) .
\end{aligned}
$$


The lower panels of Figures 5 and 6 plot both surplus values under the optimal and the zero inflation policy, respectively. Not surprisingly, both surplus values behave fairly symmetrically; in a boom, for instance, the stickiness of the nominal wage leads the firm's surplus to increase and the worker's to shrink. In both cases, firm and worker always enjoy a positive surplus in this group of firms, confirming the results from the upper panels. Notice that fluctuations in the surplus values are much larger under the zero inflation policy, which leads the former to come closer to the zero bound. This is due to better stabilization of the economy under the optimal policy. This is also the reason why the wage comes closer to the boundaries of the bargaining set under the zero inflation policy.

\section{Further discussion}

\subsection{Output gap targeting}

So far I haven't made any reference to the output gap, i.e. the gap between the actual and the efficient level of output. This variable features prominently in monetary policy discussions in the New Keynesian literature. ${ }^{42}$ Efficient output is the output level in the social planner economy, or equivalently (under my assumption of an efficient steady state) the output level that would be observed in the decentralized economy if both prices and wages were flexible. Aggregate output is given by $y_{t} \equiv$ $\int_{0}^{1} y_{i t} d i=A_{t} f\left(h_{t} n_{t}, \bar{k}\right)$. In terms of log-deviations from steady state,

$$
\hat{y}_{t} \equiv a_{t}+\alpha\left(\hat{n}_{t}+\hat{h}_{t}\right) .
$$

Conditional on the employment stock, efficient output in any period $t$ is given by

$$
\hat{y}_{t}^{e} \equiv a_{t}+\alpha\left(\hat{n}_{t}+\hat{h}_{t}^{e}\right)
$$

where $\hat{h}_{t}^{e}$ is the efficient level of hours. Using equations (34) and (36) to substitute for $\widehat{m p l}_{t}$ and $\hat{c}_{t}$ in the social planner's hours decision, equation (47), I obtain the following expression, which implicitly defines $\hat{h}_{t}^{e}$,

$$
a_{t}-(1-\alpha)\left(\hat{n}_{t}+\hat{h}_{t}^{e}\right)=\eta \hat{h}_{t}^{e}+\sigma^{-1} s_{c}^{-1}\left\{a_{t}+\alpha\left(\hat{n}_{t}+\hat{h}_{t}^{e}\right)-s_{v}\left[(1+\psi) \hat{v}_{t}^{e}-\hat{n}_{t}\right]\right\} .
$$

$\hat{v}_{t}^{e}$ is the efficient level of vacancies and is determined by the social planner's job creation decision, equation (48). ${ }^{43}$ Since it is not possible to obtain an explicit

\footnotetext{
${ }^{42}$ See e.g. Woodford (2003) and Clarida et al. (1999).

${ }^{43}$ In equation (48), the efficient levels of labor market tightness and the average vacancy rate are given by $\hat{\theta}_{t}^{e}=\hat{v}_{t}^{e}-\left(-\frac{u}{n} \hat{n}_{t}\right)$ and $\hat{z}_{t}^{e}=\hat{v}_{t}^{e}-\hat{n}_{t}$, respectively.
} 
solution for $\hat{v}_{t}^{e}$ in terms of the economy's state $\left(a_{t}, \hat{n}_{t}\right)$, it is useful at this point to assume that hiring costs are small as a fraction of GDP. In particular, I assume that $s_{v}$ is first order in the size of the exogenous shock,

Assumption $3 s_{v}=O^{1}$

Therefore, first order terms multiplied by $s_{v}$ are actually of second order. ${ }^{44}$ Using this, I can eliminate the $\hat{z}_{t}$ and $\hat{n}_{t}$ terms from (53). This, together with $s_{c}=1-s_{v}=$ $1+O^{1}$, allows me to write

$$
\hat{h}_{t}^{e}=\frac{1-\sigma^{-1}}{\alpha\left(\sigma^{-1}+\omega\right)} a_{t}-\frac{\omega_{p}+\sigma^{-1}}{\sigma^{-1}+\omega} \hat{n}_{t}+O^{2},
$$

where $\omega \equiv \omega_{w}+\omega_{p}$, and $\omega_{w} \equiv \frac{\eta}{\alpha}$ and $\omega_{p} \equiv \frac{1-\alpha}{\alpha}$ are the output elasticities of the marginal disutility and the marginal product of labor, respectively. The efficient level of output is then given by

$$
\hat{y}_{t}^{e}=\frac{1+\omega}{\sigma^{-1}+\omega} a_{t}+\frac{\eta}{\sigma^{-1}+\omega} \hat{n}_{t}+O^{2} .
$$

Notice that $\hat{y}_{t}^{e}$ is increasing in $\hat{n}_{t}$. The larger the number of workers, the greater the amount of output that can be produced before the marginal disutility of work catches up with the marginal product of labor. The output gap is given by

$$
x_{t} \equiv \hat{y}_{t}-\hat{y}_{t}^{e}=\hat{y}_{t}-\left[\frac{1+\omega}{\sigma^{-1}+\omega} a_{t}+\frac{\eta}{\sigma^{-1}+\omega} \hat{n}_{t}\right]+O^{2} .
$$

Under Assumption 3, consumption equals output up to a first-order approximation, $\hat{c}_{t}=\hat{y}_{t}+O^{2}$. Combining this with (35), (34) and (52), I can express real marginal costs as

$$
\hat{\varphi}_{t}=\left(\sigma^{-1}+\omega\right) x_{t}+O^{2}
$$

This in turn allows me to write the Phillips curve, equation (38), as

$$
\pi_{t}=\kappa x_{t}+\beta E_{t} \pi_{t+1}+O^{2}
$$

where $\kappa \equiv\left(\sigma^{-1}+\omega\right) \kappa_{p}$. Therefore, under the assumption of small hiring costs, closing the output gap is equivalent to eliminating inflation up to a first order approximation. This result stems from the following. First, conditional on the employment stock, stabilizing output is equivalent to stabilizing hours per worker. Second, hours

\footnotetext{
${ }^{44}$ Notice that the calibrated value of $s_{v}, 0.01$, is consistent with Assumption 3.
} 
determination is privately efficient and therefore independent of wages, such that hours are distorted by price stickiness and inefficiency in vacancy posting, but not by wage stickiness. Therefore, if vacancy posting costs are small as a fraction of output, the policy that eliminates the distortionay effects of price stickiness (i.e. the zero inflation policy) is approximately the same as the one that stabilizes output.

This result has important policy implications. As shown by Woodford (2003, sections 3.4 and 6.4.4), in the Erceg et al. (2000) model stabilizing the output gap is equivalent to stabilizing a weighted average of price and wage inflation, with weights depending on the relative stickiness of prices and wages. Since price and wage inflation receive most of the weight in the loss function in a plausible calibration of that model, it turns out that output gap stabilization is nearly optimal for any degree of relative wage stickiness (and exactly optimal in one parametric case). However, in the present model, by equation (55) stabilizing the output gap is equivalent to stabilizing inflation, with an error that is second order. Therefore, the welfare losses from output gap targeting should be similar to those from inflation targeting. The dotted line in Figure 4 shows the net expected welfare loss under the following rule,

$$
\hat{y}_{t}=\frac{1+\omega}{\sigma^{-1}+\omega} a_{t}+\frac{\eta}{\sigma^{-1}+\omega} \hat{n}_{t}
$$

i.e. when the central bank closes the output gap up to a first order approximation. ${ }^{45}$ Because this policy is approximately equivalent to the zero inflation policy, it also encounters the latter's problems, and it becomes more and more suboptimal as the contract length increases. Under 12-month contracts, net welfare losses are $51 \%$ higher than under the optimal commitment.

\subsection{Replacing staggered wages with a wage norm}

Modelling wage determination as the result of staggered bargaining of nominal wages is motivated by the evidence that nominal wages are indeed staggered (see Taylor, 1999). Using the Calvo mechanism of wage staggering has the advantage that the parameter regulating the degree of staggering, $\delta_{w}$, can be calibrated empirically, to match either the fraction of nominal wages that change in a typical month, or the average duration of nominal wage contracts (which in the model equals $\frac{1}{1-\delta_{w}}$ ). By contrast, most studies that integrate New Keynesian and search and matching models assume that real wages are set as a weighted average of the Nash real wage and

\footnotetext{
${ }^{45}$ Notice from Figure 4 that, when wages are flexible, the net welfare loss under output gap targeting is not zero. This is because there is a second-order difference between the $\pi_{t}=0$ policy (which attains zero net welfare loss when wages are flexible) and the policy described by (56).
} 
a symmetric real wage norm. ${ }^{46}$ This wage norm can take many forms, but last period's wage or a constant wage are usually considered. As emphasized by Gertler and Trigari (2006), calibrating the partial adjustment coefficient in this kind of wage equations is an ad hoc exercise. However, beyond the question of empirical applicability, how wage determination is modelled also has important policy implications. Staggering of nominal wages creates inefficient wage dispersion, and targeting zero inflation only makes this problem worse. If wages follow instead a partial adjustment equation based on a symmetric wage norm, there is no wage dispersion. As a consequence, considering a wage norm rather than staggered wages is likely to underestimate the extent to which targeting zero inflation is suboptimal.

Replacing staggered wages with a wage norm in this model is straightforward. Equations (29) and (30) are replaced by

$$
\frac{W_{t}}{P_{t}} \equiv w_{t}=\delta w_{t}^{n o r m}+(1-\delta) w_{t}^{n a s h},
$$

where $w_{t}^{\text {norm }}$ is the wage norm, $w_{t}^{\text {nash }}$ is still given by (23), without subscript $i$, and $\delta \in[0,1]$. In the absence of wage dispersion, the loss function is given by (45) without the $\pi_{w t}^{2}$ term. The model remains unchanged otherwise. Figure 7 plots the net expected welfare loss under the optimal and the zero inflation policy when the wage norm is last period's real wage, $w_{t}^{\text {norm }}=w_{t-1}$. The only distortion created now by wage rigidity is inefficient job creation. As the figure makes clear, zero inflation is nearly optimal for any value of $\delta$ (in fact, both lines are indistinguishable). Since wage inflation no longer creates a welfare loss, price inflation now receives almost all of the weight (95\%) in the loss function. As a result, the trade-off between preventing price dispersion (i.e. inflation) and preventing distortions in the unemployment path is resolved in favor of the former. Figure 8 repeats the same exercise for the case in which the wage norm is the steady-state real wage, $w_{t}^{n o r m}=w$. Again, the absence of wage dispersion makes zero inflation nearly optimal for any degree of real wage rigidity.

There is a caveat to these results. The Calvo model of price staggering, with its constant probability of price adjustment, is likely to exaggerate the degree of price dispersion, because the age distribution of prices has a very long tail (i.e. there is always a non-negligible fraction of firms with very old prices). More realistic alternatives, such as the Taylor model (where prices last for a fixed number of periods) or Sheedy's (2006) model (where adjustment probabilities are increasing in the age of the contract), would deliver smaller welfare losses from targeting zero inflation.

\footnotetext{
${ }^{46}$ This is the approach taken in Blanchard and Gali (forthcoming; 2006), Krause and Lubik (2005) and Christoffel and Linzert (2005). The wage norm was introduced by Hall (2005).
} 


\section{Conclusions}

In this paper I have analyzed optimal monetary policy in an economy with search and matching frictions in the labor market, as well as staggered nominal wage and price contracts. So far, the literature had integrated the New Keynesian and the search and matching paradigms with an exclusively positive focus, namely to improve the empirical performance of general equilibrium models of the monetary transmission mechanism and to allow these models to say something about labor market phenomena such as unemployment, vacancies and job flows. ${ }^{47}$

I have shown that, when wages are Nash bargained in every period and the economy's steady state is efficient, the central bank can replicate the first-best equilibrium by targeting zero inflation. However, the empirically relevant case is that in which only a fraction of firms renegotiate nominal wages. This creates two types of distortion when the economy is hit by real shocks: inefficient job creation and dispersion in hiring rates. Keeping the price level constant only magnifies these distortions. Therefore, the optimal policy commitment allows for non-zero inflation in response to shocks: the central bank uses price inflation to accelerate the convergence of actual real wages towards their flexible-wage (Nash) counterparts. Quantitatively, the welfare loss created by the zero inflation policy turns out to be sizeable. This result contrasts with the standard New Keynesian model's recommendation of committing to constant prices even in the face of real shocks, also known as the "case for price stability".

The model presented here abstracts from important labor market regulations that constrain firms' ability to adjust employment and hours per employee in response to shocks. Such regulations include firing costs, overtime premia and limitations on working hours. It would be interesting to incorporate the latter in this framework, so as to understand their influence on the monetary transmission mechanism and optimal monetary policy. Given the considerable difference in labor market regulations between two major monetary areas like the US and the EU, this should be high on the monetary policy research agenda.

\footnotetext{
${ }^{47}$ The only exception is the independent work by Blanchard and Gali (2006), who also analyze optimal monetary policy under search and matching frictions.
} 


\section{A. Proofs of Lemmas}

\section{Proof of Lemma 1}

The firm's hiring decision, equation (31) in the text, can be written as

$$
\begin{gathered}
(1+\psi) \frac{s_{v}}{\lambda}\left[\hat{\varphi}_{t}+(1-\epsilon) \hat{\theta}_{t}+\psi \hat{z}_{i t}-E_{t} \hat{\beta}_{t, t+1}\right]= \\
\beta E_{t}\left\{\alpha \widehat{m p l}_{t+1}+\hat{h}_{t+1}\right)+\psi \frac{s_{v}}{\lambda}(1+\psi) \hat{z}_{i t+1}+\left(\alpha+\psi s_{v}\right) \hat{\varphi}_{t+1}-s_{w} \hat{w}_{i t+1} \\
\left.+(1-\lambda)(1+\psi) \frac{s_{v}}{\lambda}\left[\hat{\varphi}_{t+1}+(1-\epsilon) \hat{\theta}_{t+1}\right]\right\} .
\end{gathered}
$$

I now make the following guess

$$
\hat{z}_{i t}=\hat{z}_{t}-\tau_{z}\left(\log W_{i t}-\log W_{t}\right)
$$

which implies

$$
\hat{z}_{i t}^{0}=\hat{z}_{t}^{0}-\tau_{z}\left(\log W_{i t-1}-\log W_{t-1}\right),
$$

where $\hat{z}_{t}^{0} \equiv E_{i}^{0} \hat{z}_{i t}^{0}$ is the average vacancy rate across non-renegotiating firms. I have also used the fact that, since non-renegotiating firms are randomly chosen, this group's average wage is just last period's wage index. Inserting (A2) in (A1), I obtain

$$
\begin{gathered}
(1+\psi) \frac{s_{v}}{\lambda}\left[\hat{\varphi}_{t}+(1-\epsilon) \hat{\theta}_{t}+\psi \hat{z}_{i t}-E_{t} \hat{\beta}_{t, t+1}\right]= \\
\beta E_{t}\left\{\alpha \widehat{m p l}_{t+1}+\hat{h}_{t+1}\right)+\psi \frac{s_{v}}{\lambda}(1+\psi)\left[\delta_{w}\left(\hat{z}_{t+1}^{0}-\tau_{z} \tilde{w}_{i t}\right)+\left(1-\delta_{w}\right) \hat{z}_{t+1}^{*}\right]+\left(\alpha+\psi s_{v}\right) \hat{\varphi}_{t+1} \\
\left.-s_{w}\left[\delta_{w} \hat{w}_{i t+1}^{0}+\left(1-\delta_{w}\right) \hat{w}_{t+1}^{*}\right]+(1-\lambda)(1+\psi) \frac{s_{v}}{\lambda}\left[\hat{\varphi}_{t+1}+(1-\epsilon) \hat{\theta}_{t+1}\right]\right\}
\end{gathered}
$$

where $\tilde{w}_{i t} \equiv \log W_{i t}-\log W_{t}$ is the firm's relative wage and $\hat{z}_{t+1}^{*}$ is the common vacancy rate of renegotiating firms. I can express a non-renegotiating firm's real wage as

$$
\hat{w}_{i t+1}^{0}=\log W_{i t}-\log P_{t+1}-\log w=\tilde{w}_{i t}+\log W_{t}-\log P_{t+1}-\log w .
$$

This allows me to write

$$
\begin{gathered}
(1+\psi) \frac{s_{v}}{\lambda}\left[\hat{\varphi}_{t}+(1-\epsilon) \hat{\theta}_{t}+\psi \hat{z}_{i t}-E_{t} \hat{\beta}_{t, t+1}\right]= \\
\beta E_{t}\left\{\alpha\left(\widehat{m p l}_{t+1}+\hat{h}_{t+1}\right)+\psi \frac{s_{v}}{\lambda}(1+\psi)\left(\hat{z}_{t+1}-\delta_{w} \tau_{z} \tilde{w}_{i t}\right)+\left(\alpha+\psi s_{v}\right) \hat{\varphi}_{t+1}\right. \\
\left.-s_{w}\left[\delta_{w} \tilde{w}_{i t}+\hat{w}_{t+1}\right]+(1-\lambda)(1+\psi) \frac{s_{v}}{\lambda}\left[\hat{\varphi}_{t+1}+(1-\epsilon) \hat{\theta}_{t+1}\right]\right\}
\end{gathered}
$$


where I have also used $\log W_{t+1}=\delta_{w} \log W_{t}+\left(1-\delta_{w}\right) \log W_{t+1}^{*}$, which is equation (30) in the text $\log$-linearized. Averaging across $i$, and using $E_{i} \tilde{w}_{i t}=0$, I obtain

$$
\begin{gathered}
(1+\psi) \frac{s_{v}}{\lambda}\left[\hat{\varphi}_{t}+(1-\epsilon) \hat{\theta}_{t}+\psi \hat{z}_{t}-E_{t} \hat{\beta}_{t, t+1}\right]= \\
\beta E_{t}\left\{\alpha\left(\widehat{m p l}_{t+1}+\hat{h}_{t+1}\right)+\psi \frac{s_{v}}{\lambda}(1+\psi) \hat{z}_{t+1}+\left(\alpha+\psi s_{v}\right) \hat{\varphi}_{t+1}\right. \\
\left.-s_{w} \hat{w}_{t+1}+(1-\lambda)(1+\psi) \frac{s_{v}}{\lambda}\left[\hat{\varphi}_{t+1}+(1-\epsilon) \hat{\theta}_{t+1}\right]\right\},
\end{gathered}
$$

which is equation (32) in the text. Substracting (A4) from (A3), and using my guess, I obtain

$$
\begin{aligned}
(1+\psi) \frac{s_{v}}{\lambda} \psi\left(\hat{z}_{i t}-\hat{z}_{t}\right) & =-(1+\psi) \frac{s_{v}}{\lambda} \psi \tau_{z} \tilde{w}_{i t} \\
& =\beta E_{t}\left\{-\psi \frac{s_{v}}{\lambda}(1+\psi) \delta_{w} \tau_{z} \tilde{w}_{i t}-s_{w} \delta_{w} \tilde{w}_{i t}\right\}
\end{aligned}
$$

This implies

$$
\tau_{z}=\frac{\beta \delta_{w} s_{w}}{\left(1-\beta \delta_{w}\right)(1+\psi) \frac{s_{v}}{\lambda} \psi}
$$

\section{Proof of Lemma 2}

I define $\phi \equiv s_{w}^{-1}(1-\varepsilon) \psi s_{v}(1+\psi) \tau_{z}$, such that equation (41) in the text can be expressed as $\hat{w}_{i t+s}^{\text {nash }}=\hat{w}_{t+s}^{\text {nash }}-\phi\left(\log W_{i t}^{*}-\log W_{t+s}\right)$. Inserting this into (39), I obtain

$$
\begin{aligned}
0 & =E_{t} \sum_{s=0}^{\infty} \beta^{s}(1-\lambda)^{s} \delta_{w}^{s}\left[\log W_{i t}^{*}-\log P_{t+s}-\log w-\hat{w}_{t+s}^{n a s h}+\phi\left(\log W_{i t}^{*}-\log W_{t+s}\right)\right] \\
& \left.=E_{t} \sum_{s=0}^{\infty} \beta^{s}(1-\lambda)^{s} \delta_{w}^{s}\left[(1+\phi) \log W_{i t}^{*}+\hat{w}_{t+s}-\hat{w}_{t+s}^{n a s h}-(1+\phi) \log W_{t+s}\right)\right] .
\end{aligned}
$$

Notice that all renegotiating firms will agree on the same nominal wage, $\log W_{i t}^{*}=$ $\log W_{t}^{*}$. Solving for $\log W_{t}^{*}$ yields

$$
(1+\phi) \log W_{t}^{*}=\left[1-(1-\lambda) \beta \delta_{w}\right] E_{t} \sum_{s=0}^{\infty} \beta^{s}(1-\lambda)^{s} \delta_{w}^{s}\left[\hat{w}_{t+s}^{n a s h}-\hat{w}_{t+s}+(1+\phi) \log W_{t+s}\right] .
$$

Equation (A5) admits the following representation,

$$
\begin{aligned}
(1+\phi) \log W_{t}^{*}= & {\left[1-(1-\lambda) \beta \delta_{w}\right]\left[\hat{w}_{t}^{\text {nash }}-\hat{w}_{t}+(1+\phi) \log W_{t}\right] } \\
& +(1-\lambda) \beta \delta_{w} E_{t}(1+\phi) \log W_{t+1}^{*},
\end{aligned}
$$


or alternatively

$$
\begin{aligned}
(1+\phi)\left(\log W_{t}^{*}-\log W_{t}\right)= & {\left[1-(1-\lambda) \beta \delta_{w}\right]\left(\hat{w}_{t}^{\text {nash }}-\hat{w}_{t}\right) } \\
& +(1-\lambda) \beta \delta_{w} E_{t}(1+\phi)\left(\log W_{t+1}^{*}-\log W_{t}\right) .
\end{aligned}
$$

The law of motion of the wage index, equation (30) in the text, can be approximated by

$$
\log W_{t}^{*}-\log W_{t}=\frac{\delta_{w}}{1-\delta_{w}}\left(\log W_{t}-\log W_{t-1}\right)=\frac{\delta_{w}}{1-\delta_{w}} \pi_{w t} .
$$

Using this, equation (A6) can be expressed as

$$
\begin{aligned}
(1+\phi) \frac{\delta_{w}}{1-\delta_{w}} \pi_{w t}= & {\left[1-(1-\lambda) \beta \delta_{w}\right]\left(\hat{w}_{t}^{n a s h}-\hat{w}_{t}\right) } \\
& +(1-\lambda) \beta \frac{\delta_{w}}{1-\delta_{w}} E_{t}(1+\phi) \pi_{w t+1} .
\end{aligned}
$$

Dividing (A7) by $(1+\phi) \frac{\delta_{w}}{1-\delta_{w}}$, I finally obtain equation (42) in the text.

\section{Proof of Lemma 3}

Log-linearizing the worker surplus, equation (27) for any $i$, I obtain

$$
S_{y}^{w} \hat{S}_{i t}^{w}=s_{w} \hat{w}_{i t}-s_{\underline{w}} \widehat{\underline{w}}_{t}+(1-\lambda) \beta S_{y}^{w} E_{t}\left[\hat{\beta}_{t, t+1}+\delta_{w} \hat{S}_{i t+1}^{w 0}+\left(1-\delta_{w}\right) \hat{S}_{t+1}^{w *}\right],
$$

where $S_{y}^{w} \equiv \frac{n S^{w}}{y}$ is total worker surplus as a fraction of GDP. I now make the following guess,

$$
\hat{S}_{i t}^{w}=\hat{S}_{t}^{w}+\tau_{w} \tilde{w}_{i t}
$$

For non-renegotiating firms, I can then write

$$
\hat{S}_{i t}^{w 0}=\hat{S}_{t}^{w 0}+\tau_{w} \tilde{w}_{i t-1},
$$

where $\hat{S}_{t}^{w 0}$ is the average worker surplus across non-renegotiating firms. Using (A10) as well as $\hat{w}_{i t}=\tilde{w}_{i t}+\hat{w}_{t}$ in (A8), I can write

$$
\begin{aligned}
S_{y}^{w} \hat{S}_{i t}^{w}= & s_{w}\left(\tilde{w}_{i t}+\hat{w}_{t}\right)-s_{\underline{w}} \widehat{\underline{w}}_{t} \\
& +(1-\lambda) \beta S_{y}^{w} E_{t}\left[\hat{\beta}_{t, t+1}+\delta_{w}\left(\hat{S}_{t+1}^{w 0}+\tau_{w} \tilde{w}_{i t}\right)+\left(1-\delta_{w}\right) \hat{S}_{t+1}^{w *}\right] .
\end{aligned}
$$

I now average (A11) across all firms and substract the resulting expression from (A11). This, combined with (A9), yields

$$
S_{y}^{w}\left(\hat{S}_{i t}^{w}-\hat{S}_{t}^{w}\right)=S_{y}^{w} \tau_{w} \tilde{w}_{i t}=s_{w} \tilde{w}_{i t}+(1-\lambda) \beta S_{y}^{w} \delta_{w} \tau_{w} \tilde{w}_{i t},
$$


which implies

$$
\tau_{w}=\frac{s_{w}}{\left[1-(1-\lambda) \beta \delta_{w}\right] S_{y}^{w}} .
$$

Similarly, log-linearization of the firm surplus, equation (26) for any $i$, yields

$$
S_{y}^{f} \hat{S}_{i t}^{f}=s_{\bar{w}} \widehat{\bar{w}}_{i t}-s_{w} \hat{w}_{i t}+(1-\lambda) \beta S_{y}^{f} E_{t}\left[\hat{\beta}_{t, t+1}+\delta_{w} \hat{S}_{i t+1}^{f 0}+\left(1-\delta_{w}\right) \hat{S}_{t+1}^{f *}\right],
$$

where $S_{y}^{f} \equiv \frac{n S^{f}}{y}$. I now guess

$$
\hat{S}_{i t}^{f}=\hat{S}_{t}^{f}-\tau_{f} \tilde{w}_{i t}
$$

This implies that, for non-renegotiating firms,

$$
\hat{S}_{i t}^{f 0}=\hat{S}_{t}^{f 0}-\tau_{f} \tilde{w}_{i t-1}
$$

where $\hat{S}_{t}^{f 0}$ is the average firm surplus across non-renegotiating firms. From the definition of $\bar{w}_{i t}$, equation (19), it follows that, up a log-linear approximation,

$$
\begin{aligned}
s_{w} \widehat{\bar{w}}_{i t} & =s_{w} \widehat{\bar{w}}_{t}+\psi s_{v}(1+\psi) \tilde{z}_{i t} \\
& =s_{w} \widehat{\bar{w}}_{t}-\psi s_{v}(1+\psi) \tau_{z} \tilde{w}_{i t}
\end{aligned}
$$

where in the second equality I have used Lemma 1. Using (A14), (A15) and $\hat{w}_{i t}=$ $\tilde{w}_{i t}+\hat{w}_{t}$ in (A12), I obtain

$$
\begin{aligned}
S_{y}^{f} \hat{S}_{i t}^{f}= & s_{\bar{w}} \widehat{\bar{w}}_{t}-\psi s_{v}(1+\psi) \tau_{z} \tilde{w}_{i t}-s_{w}\left(\tilde{w}_{i t}+\hat{w}_{t}\right) \\
& +(1-\lambda) \beta S_{y}^{f} E_{t}\left[\hat{\beta}_{t, t+1}+\delta_{w}\left(\hat{S}_{t+1}^{f 0}-\tau_{f} \tilde{w}_{i t}\right)+\left(1-\delta_{w}\right) \hat{S}_{t+1}^{f *}\right] .
\end{aligned}
$$

Again, I average (A16) across all firms and substract the resulting expression from (A16). This, combined with (A13), yields

$$
S_{y}^{f}\left(\hat{S}_{i t}^{f}-\hat{S}_{t}^{f}\right)=-S_{y}^{f} \tau_{f} \tilde{w}_{i t}=-\psi s_{v}(1+\psi) \tau_{z} \tilde{w}_{i t}-s_{w} \tilde{w}_{i t}-(1-\lambda) \beta S_{y}^{f} \delta_{w} \tau_{f} \tilde{w}_{i t}
$$

which implies

$$
\tau_{f}=\frac{s_{w}+\psi s_{v}(1+\psi) \tau_{z}}{\left[1-(1-\lambda) \beta \delta_{w}\right] S_{y}^{f}}
$$




\section{Proof of Lemma 4}

Using Lemma 3, I can express the worker surplus in renegotiating firms in period $t+1$ as

$$
\hat{S}_{t+1}^{w *}=\hat{S}_{t+1}^{w}+\tau_{w} E_{t}\left(\log W_{t+1}^{*}-\log W_{t+1}\right) .
$$

Similarly for the firm surplus in renegotiating firms,

$$
\hat{S}_{t+1}^{f *}=\hat{S}_{t+1}^{f}-\tau_{f} E_{t}\left(\log W_{t+1}^{*}-\log W_{t+1}\right) .
$$

From the bargaining rule, equation (28) in the text, I have $\hat{S}_{t+1}^{w *}=\hat{S}_{t+1}^{f *}$, which implies

$$
\hat{S}_{t+1}^{w}=\hat{S}_{t+1}^{f}-\left(\tau_{f}+\tau_{w}\right)\left(\log W_{t+1}^{*}-\log W_{t+1}\right) .
$$

Log-linearizing the first order condition with respect to vacancies, equation (6), and using Lemmas 1 and 3 to aggregate across firms yields

$$
E_{t}\left(\hat{\beta}_{t, t+1}+\hat{S}_{t+1}^{f}\right)=\hat{\varphi}_{t}+(1-\epsilon) \hat{\theta}_{t}+\psi \hat{z}_{t} .
$$

Combining (A17) and (A18), I obtain

$$
\begin{aligned}
E_{t}\left(\hat{\beta}_{t, t+1}+\hat{S}_{t+1}^{w}\right) & =E_{t}\left(\hat{\beta}_{t, t+1}+\hat{S}_{t+1}^{f}\right)-\left(\tau_{f}+\tau_{w}\right) E_{t}\left(\log W_{t+1}^{*}-\log W_{t+1}(\mathrm{~A} 19)\right. \\
& =\hat{\varphi}_{t}+(1-\epsilon) \hat{\theta}_{t}+\psi \hat{z}_{t}-\left(\tau_{f}+\tau_{w}\right) \frac{\delta_{w}}{1-\delta_{w}} E_{t} \pi_{w t+1},
\end{aligned}
$$

where in the second equality I have used $\log W_{t+1}^{*}-\log W_{t+1}=\frac{\delta_{w}}{1-\delta_{w}} \pi_{w t+1}$.

Averaging the individual Nash wage, equation (40), and using (A19), I obtain

$$
\begin{aligned}
s_{w} \hat{w}_{t}^{\text {nash }}= & (1-\varepsilon)\left[\alpha \widehat{m p l}_{t}+\psi s_{v}(1+\psi) \hat{z}_{t}+\left(\alpha+\psi s_{v}\right) \hat{\varphi}_{t}\right]+\alpha \hat{h}_{t} \\
& +\varepsilon \alpha \frac{1+\tilde{b}}{1+\eta} \sigma^{-1} \hat{c}_{t}+\varepsilon p \beta S_{y}^{w}\left(\hat{\theta}_{t}+\hat{\varphi}_{t}+\psi \hat{z}_{t}-\tau E_{t} \pi_{w t+1}\right),
\end{aligned}
$$

where $\tau \equiv\left(\tau_{f}+\tau_{w}\right) \frac{\delta_{w}}{1-\delta_{w}}$. Using the fact that, in the steady state, $\beta S_{y}^{w}=\frac{1-\varepsilon}{\varepsilon} \beta S_{y}^{f}$ and $\beta S_{y}^{f}=(1+\psi) \frac{s_{v}}{\lambda}$, I finally obtain equation (43) in the text.

\section{B. Deriving the loss function}

Following the method pioneered by Rotemberg and Woodford (1997) and extensively analyzed in Woodford (2003, Ch. 6), I now find a second-order approximation of the welfare criterion,

$$
\sum_{t=0}^{\infty} \beta^{t} U_{t}
$$


where the period utility flow is given by

$$
U_{t} \equiv u\left(c_{t}\right)-n_{t}\left[v\left(h_{t}\right)+b\right] .
$$

I assume $u\left(c_{t}\right)=c_{t}^{1-\sigma^{-1}} /\left(1-\sigma^{-1}\right)$ and $v\left(h_{t}\right)=h_{t}^{1+\eta} /(1+\eta)$. Notice that we can express any function $x_{t}^{a}$ as $e^{a \ln x_{t}}$. We can then expand every function in the logarithm of its arguments around their steady-state levels, $\ln x$. This way, I obtain the following approximation of $u\left(c_{t}\right)$,

$$
\begin{aligned}
u\left(c_{t}\right) & =u(c)\left(1-\sigma^{-1}\right)\left(\hat{c}_{t}+\frac{1-\sigma^{-1}}{2} \hat{c}_{t}^{2}\right)+t . i . p .+O^{3} \\
& =u^{\prime}(c) y\left(s_{c} \hat{c}_{t}+\frac{1-\sigma^{-1}}{2} s_{c} \hat{c}_{t}^{2}\right)+t . i . p .+O^{3},
\end{aligned}
$$

where $O^{k}$ indicates terms of order $k$-th and higher in the size of the shocks and t.i.p. represents terms independent of policy. In the second equality I have used $u(c)\left(1-\sigma^{-1}\right)=u^{\prime}(c) c$ and $c=s_{c} y$. Similarly, I make the following approximation

$$
\begin{aligned}
n_{t} v\left(h_{t}\right) & \left.=n v(h)\left[(1+\eta)\left(\hat{h}_{t}+\frac{1+\eta}{2} \hat{h}_{t}^{2}\right)+\hat{n}_{t}+\frac{1}{2} \hat{n}_{t}^{2}+(1+\eta) \hat{h}_{t} \hat{n}_{t}\right]+\text { t.i.p. }+ \text { (B } 2\right) \\
& =u^{\prime}(c) y\left[\alpha\left(\hat{h}_{t}+\frac{1+\eta}{2} \hat{h}_{t}^{2}\right)+\frac{\alpha}{1+\eta}\left(\hat{n}_{t}+\frac{1}{2} \hat{n}_{t}^{2}\right)+\alpha \hat{h}_{t} \hat{n}_{t}\right]+t . i . p .+O^{3},
\end{aligned}
$$

were in the second equality I have used the fact that $v(h)=\frac{v^{\prime}(h) h}{1+\eta}$, my assumption of efficient steady state hours, $v^{\prime}(h)=u^{\prime}(c) m p l$, as well as $m p l=\alpha \frac{y}{n h}$. The term $n_{t} b$ can be approximated by

$$
\begin{aligned}
n_{t} b & =n v(h) \tilde{b}\left(\hat{n}_{t}+\frac{1}{2} \hat{n}_{t}^{2}\right)+t . i . p .+O^{3} \\
& =u^{\prime}(c) y \frac{\alpha \tilde{b}}{1+\eta}\left(\hat{n}_{t}+\frac{1}{2} \hat{n}_{t}^{2}\right)+t . i . p .+O^{3}
\end{aligned}
$$

where $\tilde{b} \equiv \frac{b}{v(h)}$.

Combining (B1), (B2) and (B3), the flow utility of the household can be approximated by

$$
\begin{aligned}
U_{t}= & u^{\prime}(c) y\left\{s_{c} \hat{c}_{t}-\alpha \hat{h}_{t}-\alpha \frac{1+\tilde{b}}{1+\eta} \hat{n}_{t}+\frac{1}{2}\left[\left(1-\sigma^{-1}\right) s_{c} \hat{c}_{t}^{2}\right.\right. \\
& \left.\left.-\alpha \frac{1+\tilde{b}}{1+\eta} \hat{n}_{t}^{2}-\alpha(1+\eta) \hat{h}_{t}^{2}-2 \alpha \hat{h}_{t} \hat{n}_{t}\right]\right\}+ \text { t.i.p. }+O^{3} .
\end{aligned}
$$




\section{The aggregate resource constraint}

In order to eliminate the linear terms in $\hat{c}_{t}$ and $\hat{h}_{t}$ in equation (B4), I need to approximate the aggregate resource constraint. Individual hiring costs can be written as

$\frac{\chi}{1+\psi} z_{i t}^{1+\psi} n_{i t}=h c\left\{(1+\psi) \hat{z}_{i t}+\hat{n}_{i t}+\frac{1}{2}\left[(1+\psi)^{2} \hat{z}_{i t}^{2}+\hat{n}_{i t}^{2}+2(1+\psi) \hat{z}_{i t} \hat{n}_{i t}\right]\right\}+t . i . p .+O^{3}$,

where $h c \equiv \frac{\chi}{1+\psi} z^{1+\psi} n$ is hiring costs in the steady state. Total employment $n_{t} \equiv$ $\int n_{i t} d i$ and the average hiring rate $z_{t} \equiv \int \frac{n_{i t}}{n_{t}} z_{i t} d i$ can be approximated, respectively, by

$$
\begin{gathered}
\hat{n}_{t}=E_{i} \hat{n}_{i t}+\frac{1}{2} \operatorname{Var}_{i} \hat{n}_{i t}+O^{3}, \\
\hat{z}_{t}=E_{i} \hat{z}_{i t}+\frac{1}{2} \operatorname{Var}_{i} \hat{z}_{i t}+E_{i} \hat{n}_{i t} \hat{z}_{i t}-\hat{n}_{t} \hat{z}_{t}+O^{3},
\end{gathered}
$$

where for any variable $e_{i t}, E_{i} e_{i t} \equiv \int_{0}^{1} e_{i t} d i$ and $\operatorname{Var}_{i} e_{i t} \equiv E_{i}\left(e_{i t}-E_{i} e_{i t}\right)^{2}$ denote its cross-sectional average and variance, respectively. I have also used the identity $E_{i} \hat{n}_{i t}^{2}=\operatorname{Var}_{i} \hat{n}_{i t}+\left(E_{i} \hat{n}_{i t}\right)^{2}$ and the fact that $\hat{n}_{t}^{2}=\left(E_{i} \hat{n}_{i t}\right)^{2}+O^{3}$ (and similarly for $\hat{z}_{t}$ ). On the other hand, the average hiring rate can also be written as $z_{t}=\frac{v_{t}}{n_{t}}$, which allows me to write $\hat{z}_{t}=\hat{v}_{t}-\hat{n}_{t}$. Combining this with equations (B5), (B6) and (B7), I can write total hiring costs as

$$
\begin{aligned}
\int_{0}^{1} \frac{\chi}{1+\psi} \hat{z}_{i t}^{1+\psi} \hat{n}_{i t} d i= & h c\left\{(1+\psi) \hat{v}_{t}-\psi \hat{n}_{t}+\frac{1}{2}\left[\left((1+\psi) \hat{v}_{t}-\psi \hat{n}_{t}\right)^{2}\right.\right. \\
& \left.\left.+\psi(1+\psi) \operatorname{Var}_{i} \hat{z}_{i t}\right]\right\}+ \text { t.i.p. }+O^{3} .
\end{aligned}
$$

Using (B8), the aggregate resource constraint, $A_{t} f\left(h_{t} n_{t}, \bar{k}\right)=\int \frac{\chi}{1+\psi}\left(\frac{v_{i t}}{n_{i t}}\right)^{1+\psi} n_{i t} d i+$ $c_{t} \Delta_{t}$, admits the following approximation,

$$
\begin{aligned}
s_{c} \hat{c}_{t}-\alpha \hat{h}_{t}= & a_{t}+\left(\alpha+s_{v} \psi\right) \hat{n}_{t}-s_{v}(1+\psi) \hat{v}_{t}-s_{c} \hat{\Delta}_{t}+\frac{1}{2}\left\{\left[a_{t}+\alpha\left(\hat{n}_{t}+\hat{h}_{t}\right)\right]^{2}(B)\right) \\
& \left.-s_{c} \hat{c}_{t}^{2}-s_{v}\left[\left((1+\psi) \hat{v}_{t}-\psi \hat{n}_{t}\right)^{2}+\psi(1+\psi) \operatorname{Var}_{i} \hat{z}_{i t}\right]\right\}+O^{3} .
\end{aligned}
$$


Notice that $\hat{\Delta}_{t}^{2}$ does not appear in (B9): as I show below, $\hat{\Delta}_{t}$ is already a second order term. Inserting (B9) in (B4), I obtain

$$
\begin{aligned}
U_{t}= & u^{\prime}(c) y\left\{\left(\alpha \frac{\eta-\tilde{b}}{1+\eta}+s_{v} \psi\right) \hat{n}_{t}-s_{v}(1+\psi) \hat{v}_{t}-s_{c} \hat{\Delta}_{t}\right. \\
& +\frac{1}{2}\left[\left(a_{t}+\alpha\left(\hat{n}_{t}+\hat{h}_{t}\right)\right)^{2}-\sigma^{-1} s_{c} \hat{c}_{t}^{2}-\alpha \frac{1+\tilde{b}}{1+\eta} \hat{n}_{t}^{2}-\alpha(1+\eta) \hat{h}_{t}^{2}-2 \alpha \hat{h}_{t} \hat{n}_{t}\right. \\
& \left.\left.-s_{v}\left[\left((1+\psi) \hat{v}_{t}-\psi \hat{n}_{t}\right)^{2}+\psi(1+\psi) \operatorname{Var}_{i} \hat{z}_{i t}\right]\right]\right\}+t . i . p .+O^{3} .
\end{aligned}
$$

\section{The Beveridge curve}

In order to eliminate the remaining linear terms in (B10), I perform the following second order approximation of the Beveridge curve, $n_{t+1}=(1-\lambda) n_{t}+v_{t}^{\epsilon} u_{t}^{1-\epsilon}$,

$$
\hat{n}_{t+1}+\frac{\hat{n}_{t+1}^{2}}{2}=(1-\lambda)\left(\hat{n}_{t}+\frac{\hat{n}_{t}^{2}}{2}\right)+\lambda\left\{\epsilon \hat{v}_{t}+(1-\epsilon) \hat{u}_{t}+\frac{1}{2}\left[\epsilon \hat{v}_{t}+(1-\epsilon) \hat{u}_{t}\right]^{2}\right\}+O^{3},
$$

where I have used the fact that $\frac{m}{n}=\lambda$. On the other hand, the unemployment rate, $u_{t}=1-n_{t}$, admits the following approximation

$$
\hat{u}_{t}=-\frac{p}{\lambda}\left(\hat{n}_{t}+\frac{\hat{n}_{t}^{2}}{2}\right)-\frac{\hat{u}_{t}^{2}}{2}+O^{3},
$$

where I have used the steady-state Beveridge curve, $\frac{n}{u}=\frac{p}{\lambda}$. Inserting (B12) into (B11), multiplying both sides by $\beta^{t}$ and integrating across $t$, I obtain

$$
\begin{gathered}
\sum_{t=0}^{\infty} \beta^{t}\left\{\left[\beta^{-1}-(1-\lambda-(1-\epsilon) p)\right] \hat{n}_{t}-\lambda \epsilon \hat{v}_{t}\right\} \\
=\sum_{t=0}^{\infty} \beta^{t} \frac{1}{2}\left\{\lambda\left[\epsilon \hat{v}_{t}+(1-\epsilon) \hat{u}_{t}\right]^{2}-\lambda(1-\epsilon) \hat{u}_{t}^{2}-\left[\beta^{-1}-(1-\lambda-(1-\epsilon) p)\right] \hat{n}_{t}^{2}\right\} \\
+O^{3}+t . i . p .
\end{gathered}
$$

where I have used the fact that $\hat{n}_{0}$ is independent of policy as of time 0 . From the job creation condition in the steady state, equation (51), I have $\beta^{-1}-[1-\lambda-(1-\epsilon) p]=$ $\frac{1}{1+\psi} s_{v}^{-1} \lambda \epsilon\left(\alpha \frac{\eta-\tilde{b}}{1+\eta}+\psi s_{v}\right)$. This allows me to rewrite (B13) as

$$
\begin{array}{r}
\sum_{t=0}^{\infty} \beta^{t}\left[\left(\alpha \frac{\eta-\tilde{b}}{1+\eta}+\psi s_{v}\right) \hat{n}_{t}-(1+\psi) s_{v} \hat{v}_{t}\right] \\
=\sum_{t=0}^{\infty} \beta^{t} \frac{1}{2}\left\{(1+\psi) s_{v}\left[\epsilon \hat{v}_{t}^{2}-(1-\epsilon) \hat{u}_{t}^{2}+2(1-\epsilon) \hat{v}_{t} \hat{u}_{t}\right]-\left(\alpha \frac{\eta-\tilde{b}}{1+\eta}+\psi s_{v}\right) \hat{n}_{t}^{2}\right\}+O^{3}+t . i . p .
\end{array}
$$


I now multiply (B10) by $\beta^{t}$ and integrate across $t$. I can then insert (B14) in the resulting expression to obtain

$$
\begin{aligned}
\sum_{t=0}^{\infty} \beta^{t} U_{t}= & \frac{u^{\prime}(c) y}{2} \sum_{t=0}^{\infty} \beta^{t}\left\{\left[a_{t}+\alpha\left(\hat{n}_{t}+\hat{h}_{t}\right)\right]^{2}-\sigma^{-1} s_{c} \hat{c}_{t}^{2}-\alpha \hat{n}_{t}^{2}-\alpha(1+\eta) \hat{h}_{t}^{2}\right. \\
& \left.-2 \alpha \hat{h}_{t} \hat{n}_{t}-(1+\psi) s_{v}\left[(1-\epsilon) \hat{\theta}_{t}^{2}+\psi \hat{z}_{t}^{2}+\psi V a r_{i} \hat{z}_{i t}\right]-2 s_{c} \hat{\Delta}_{t}\right\}+t . i . p .+O^{3},
\end{aligned}
$$

where I have used the fact that $\hat{\theta}_{t}=\hat{v}_{t}-\hat{u}_{t}$.

\section{Price dispersion and inflation}

A second order Taylor expansion of $\Delta_{t}=\int_{0}^{1}\left(\frac{P_{j t}}{P_{t}}\right)^{-\gamma} d j$ yields

$$
\hat{\Delta}_{t}+\frac{\hat{\Delta}_{t}^{2}}{2}=-\gamma\left(E_{j} \tilde{p}_{j t}-\frac{\gamma}{2} E_{j} \tilde{p}_{j t}^{2}\right)+O^{3}
$$

where $\tilde{p}_{j t} \equiv \log \left(P_{j t} / P_{t}\right)$ and I have used the fact that $\Delta_{s s}=1$. Similarly, a second order approximation of $P_{t}^{1-\gamma}=\int_{0}^{1} P_{j t}{ }^{1-\gamma} d j$, or $1=\int_{0}^{1}\left(\frac{P_{j t}}{P_{t}}\right)^{1-\gamma} d j$, yields

$$
E_{j} \tilde{p}_{j t}=\frac{\gamma-1}{2} E_{j} \tilde{p}_{j t}^{2}+O^{3}
$$

Therefore, (B16) becomes

$$
\hat{\Delta}_{t}=\frac{\gamma}{2} E_{j} \tilde{p}_{j t}^{2}+O^{3}
$$

where I have used the fact that $\hat{\Delta}_{t}^{2}$ is $O^{4}$.

A first order approximation of equation (12) in the text yields

$$
\log P_{t}^{*}-\log P_{t}=\frac{\delta_{p}}{1-\delta_{p}} \pi_{t}+O^{2}
$$

where $\pi_{t} \equiv \log \left(P_{t} / P_{t-1}\right)$ is the inflation rate. I now find an expression for $E_{j} \tilde{p}_{j t}^{2}$,

$$
\begin{aligned}
E_{j} \tilde{p}_{j t}^{2} & =\int_{0}^{\delta_{p}}\left(\log P_{j t-1}-\log P_{t}\right)^{2} d j+\int_{\delta_{p}}^{1}\left(\log P_{t}^{*}-\log P_{t}\right)^{2} d j \\
& =\delta_{p}\left(\pi_{t}^{2}+E_{j} \tilde{p}_{j t-1}^{2}\right)+\frac{\delta_{p}^{2}}{1-\delta_{p}} \pi_{t}^{2}+O^{3} \\
& =\delta_{p} E_{j} \tilde{p}_{j t-1}^{2}+\frac{\delta_{p}}{1-\delta_{p}} \pi_{t}^{2}+O^{3}
\end{aligned}
$$


where in the second equality I have used $\log P_{j t-1}-\log P_{t}=\tilde{p}_{j t-1}-\pi_{t}$, the fact that non-price-setters are randomly chosen, as well as the fact that $\pi_{t} E_{j} \tilde{p}_{j t}=O^{3}$. Multiplying both sides of (B18) by $\frac{\gamma}{2}$ and using (B17), I can write the following law of motion for the price dispersion term,

$$
\hat{\Delta}_{t}=\delta_{p} \hat{\Delta}_{t-1}+\frac{\gamma}{2} \frac{\delta_{p}}{1-\delta_{p}} \pi_{t}^{2}+O^{3}
$$

Multiplying (B19) by $\beta^{t}$, integrating forward and using the fact that $\hat{\Delta}_{-1}$ is independent of policy as of time 0 , I obtain

$$
\sum_{t=0}^{\infty} \beta^{t} \hat{\Delta}_{t}=\frac{\gamma}{2} \frac{\delta_{p}}{\left(1-\delta_{p}\right)\left(1-\beta \delta_{p}\right)} \sum_{t=0}^{\infty} \beta^{t} \pi_{t}^{2}+\text { t.i.p. }+O^{3}
$$

\section{Dispersion in hiring rates and wage inflation}

Following Proposition 6.3 in Woodford (2003), we know that, when wages are reset at random intervals in a Calvo (1983) fashion, the cross-sectional variance of wages is related to wage inflation in the following way,

$$
\operatorname{Var}_{i} \log W_{i t} \equiv \Delta_{w t}=\delta_{w} \Delta_{w t-1}+\frac{\delta_{w}}{1-\delta_{w}} \pi_{w t}^{2}+O^{3}
$$

Multiplying (B21) by $\beta^{t}$, integrating forward and using the fact that $\Delta_{w,-1}$ is independent of policy as of time 0 , I obtain

$$
\sum_{t=0}^{\infty} \beta^{t} \Delta_{w t}=\frac{\delta_{w}}{\left(1-\delta_{w}\right)\left(1-\beta \delta_{w}\right)} \sum_{t=0}^{\infty} \beta^{t} \pi_{w t}^{2}+\text { t.i.p. }+O^{3}
$$

Given that $\tilde{z}_{i t}=-\tau_{z} \tilde{w}_{i t}$, it follows that $\operatorname{Var}_{i} \hat{z}_{i t}=\tau_{z}^{2} \operatorname{Var}_{i} \log W_{i t}$. This allows me to write

$$
\sum_{t=0}^{\infty} \beta^{t} \operatorname{Var}_{i} \hat{z}_{i t}=\frac{\tau_{z}^{2} \delta_{w}}{\left(1-\delta_{w}\right)\left(1-\beta \delta_{w}\right)} \sum_{t=0}^{\infty} \beta^{t} \pi_{w t}^{2}+\text { t.i.p. }+O^{3} .
$$

Finally, inserting (B20) and (B22) into (B15) yields

$$
\begin{aligned}
\sum_{t=0}^{\infty} \beta^{t} U_{t}= & -\frac{u^{\prime}(c) y}{2} \sum_{t=0}^{\infty} \beta^{t}\left\{\lambda_{p} \pi_{t}^{2}+\lambda_{w} \pi_{w t}^{2}+\sigma^{-1} s_{c} \hat{c}_{t}^{2}-\left[a_{t}+\alpha\left(\hat{n}_{t}+\hat{h}_{t}\right)\right]^{2}+\alpha \hat{n}_{t}^{2}\right. \\
& \left.+\alpha(1+\eta) \hat{h}_{t}^{2}+2 \alpha \hat{h}_{t} \hat{n}_{t}+(1+\psi) s_{v}\left[(1-\epsilon) \hat{\theta}_{t}^{2}+\psi \hat{z}_{t}^{2}\right]\right\}+ \text { t.i.p. }+O^{3},
\end{aligned}
$$

where $\lambda_{p} \equiv s_{c} \frac{\gamma}{\kappa_{p}}, \kappa_{p} \equiv \frac{\left(1-\delta_{p}\right)\left(1-\beta \delta_{p}\right)}{\delta_{p}}$ and $\lambda_{w} \equiv(1+\psi) s_{v} \psi \frac{\tau_{z}^{2} \delta_{w}}{\left(1-\delta_{w}\right)\left(1-\beta \delta_{w}\right)}$. 


\section{References}

[1] Andolfatto, David. "Business Cycles and Labor-Market Search," American Economic Review, 86(1), 1996.

[2] Ball, Laurence and David Rome. "Real Rigidities and the Non-Neutrality of Money," Review of Economic Studies, 57(2), 1990.

[3] Barro, Robert J. "Long-term contracting, sticky prices, and monetary policy," Journal of Monetary Economics, 3(3), 1977.

[4] Benigno, Pierpaolo and Michael Woodford. "Inflation Stabilization and Welfare: the Case of a Distorted Steady State," mimeo, February 2005.

[5] Benigno, Pierpaolo and Michael Woodford. "Optimal Taxation in an RBC Model: A Linear-Quadratic Approximation," mimeo, December 2005.

[6] Bewley, Truman. Why Wages Don't Fall During a Recession, Harvard University Press, 1999.

[7] Blanchard, Olivier J. and Peter Diamond. "The Beveridge Curve," Brookings Papers on Economic Activity, 1, 1989.

[8] Blanchard, Olivier and Jordi Gali. "Real Wage Rigidities and the New Keynesian Model", forthcoming, Journal of Money, Credit and Banking.

[9] Blanchard, Olivier and Jordi Gali. "A New Keynesian Model with Unemployment," mimeo, May 2006.

[10] Calvo, Guillermo. "Staggered Prices in a Utility-Maximizing Framework," Journal of Monetary Economics, 12(3), 1983.

[11] Card, David. "Intertemporal Labor Supply: An Assessment," in Advances in Econometrics: Sixth World Congress, Christopher Sims (ed.), Cambridge University Press, 1994.

[12] Cheron, Arnaud and Francois Langot. "The Phillips and Beveridge curves revisited," Economics Letters, 69(3), 2000.

[13] Christoffel, Kai and Tobias Linzert. "The Role of Real Wage Rigidities and Labor Market Frictions for Unemployment and Inflation Dynamics," ECB Discussion Paper 556, 2005. 
[14] Clarida, Richard, Jordi Gali and Mark Gertler. "The Science of Monetary Policy: A New Keynesian Perspective," Journal of Economic Literature, 37(4), 1999.

[15] Cooley, Thomas and Edward Prescott. "Economic Growth and Business Cycles," in Frontiers of Business Cycle Research, Thomas Cooley (ed.), Princeton University Press, 1995.

[16] Cooley, Thomas and Vincenzo Quadrini. "A neoclassical model of the Phillips curve relation," Journal of Monetary Economics, 44(2), 1999.

[17] Den Haan, Wouter J., Garey Ramey and Joel Watson. "Job Destruction and Propagation of Shocks," American Economic Review, 90(3), 2000.

[18] Diamond, Peter A. "Aggregate Demand Management in Search Equilibrium," Journal of Political Economy, 90(5), 1982.

[19] Domenech, Rafael, Javier Andres and Javier Ferri. "Price Rigidity and the Volatility of Vacancies and Unemployment," Institute of International Economics, working paper no. 0601, 2006.

[20] Erceg, Christopher J., Dale W. Henderson and Andrew T. Levin. "Optimal monetary policy with staggered wage and price contracts," Journal of Monetary Economics, 46(2), 2000.

[21] Gali, Jordi and Mark Gertler. "Inflation Dynamics: A Structural Econometric Analysis," Journal of Monetary Economics, 44(2), 1999.

[22] Gali, Jordi, Mark Gertler and David Lopez-Salido. "European Inflation Dynamics", European Economic Review, 45(7), 2001.

[23] Gertler, Mark and Antonella Trigari. "Unemployment Fluctuations with Staggered Nash Wage Bargaining", mimeo, April 2006.

[24] Goodfriend, Marvin and Robert G. King. "The Case for Price Stability," in Why Price Stability?, European Central Bank, 2001.

[25] Gottschalk, Peter. "Downward Nominal Wage Flexibility: Real or Measurement Error?," IZA Discussion Paper No. 1327, 2004.

[26] Hairault, Jean-Olivier. "Labor-Market Search and International Business Cycles," Review of Economic Dynamics, 5(3), 2002. 
[27] Hall, Robert E. "Employment Fluctuations with Equilibrium Wage Stickiness." American Economics Review, 95(1), 2005.

[28] Hosios, Arthur, "On the Efficiency of Matching and Related Models of Search and Unemployment", Review of Economic Studies, 57(2), 1990.

[29] Kimball, Miles S. "The Quantitative Analytics of the Basic Neomonetarist Model," Journal of Money, Credit and Banking, 27, 1995.

[30] King, Robert G. and Alexander L. Wolman. "What Should the Monetary Authority Do when Prices are Sticky?" in J.B. Taylor (ed.), Monetary Policy Rules, University of Chicago Press, 1999.

[31] Klenow Peter J. and Oleksiy Kryvtsov. "State-Dependent or Time-Dependent Pricing: Does it Matter for Recent U.S. Inflation?" NBER Working Paper No. 11043, 2005.

[32] Krause, Michael and Thomas Lubik. "The (Ir)relevance of Real Wage Rigidity in the New Keynesian Model with Search Frictions," forthcoming, Journal of Monetary Economics.

[33] Merz, Monika. "Search in the labor market and the real business cycle," Journal of Monetary Economics, 36, 1995.

[34] Merz, Monika and Eran Yashiv. "Labor and the Market Value of the Firm," forthcoming, American Economic Review.

[35] Mortensen, Dale T. "Property Rights and Efficiency in Mating, Racing, and Related Games," American Economic Review, 72(5), 1982.

[36] Mortensen, Dale T. and Christopher A. Pissarides. "Taxes, Subsidies and Equilibrium Labor Market Outcomes," in Edmund S. Phelps (ed.), Designing Inclusion, Cambridge University Press, 2003.

[37] Moyen, Stephane and Jean-Guillaume Sahuc. "Incorporating labour market frictions into an optimising-based monetary policy model," Economic Modelling, $22(1), 2005$.

[38] Petrongolo, Barbara and Christopher A. Pissarides. "Looking into the Black Box: A Survey of the Matching Function." Journal of Economic Literature, 2001, 39(2). 
[39] Pissarides, Christopher A., "Short-Run Equilibrium Dynamics of Unemployment, Vacancies, and Real Wages", American Economic Review, 75(4), 1985.

[40] Pissarides, Christopher A. Equilibrium Unemployment Theory. MIT Press, 2000.

[41] Prescott, Edward C., "Theory ahead of business cycle measurement", Federal Reserve Bank of Minneapolis Quarterly Review, 10(4), 1986.

[42] Rotemberg, Julio and Michael Woodford, "An Optimization-Based Econometric Model for the Evaluation of Monetary Policy", NBER Macroeconomics Annual, 1997.

[43] Sbordone, Argia. "Prices and Unit Labor Costs: A New Test of Price Stickiness," Journal of Monetary Economics, 49, 2002.

[44] Sheedy, Kevin. "Structural Inflation Persistence," mimeo, november 2005.

[45] Shimer, Robert, "The Cyclicality of Hires, Separations, and Job-to-Job Transitions," mimeo, University of Chicago, January 2005.

[46] Taylor, John B., "Staggered Price and Wage Setting in Macroeconomics", in J.B. Taylor and M. Woodford (eds.), Handbook of Macroeconomics, vol. 1B, 1999 .

[47] Trigari, Antonella. "Equilibrium Unemployment, Job Flows and Inflation Dynamics," mimeo, December 2005.

[48] Trigari, Antonella. "The Role of Search Frictions and Bargaining for Inflation Dynamics," IGIER Working Paper No. 304, February 2006.

[49] Uhlig, Harald. "A toolkit for analysing nonlinear dynamic stochastic models easily," in Ramon Marimon and Andrew Scott, eds., Computational Methods for the Study of Dynamic Economies. Oxford University Press, 1999.

[50] Walsh, Carl. Monetary Theory and Policy. MIT Press, 2003.

[51] Walsh, Carl. "Labor Market Search and Monetary Shocks", in Elements of Dynamic Macroeconomic Analysis, S. Altug, J. Chadha and C. Nolan (eds.), Cambridge University Press, 2004.

[52] Walsh, Carl. "Labor Market Search, Sticky Prices and Interest Rate Rules," Review of Economic Dynamics, 8, 2005. 
[53] Woodford, Michael. Interest and Prices: Foundations of a Theory of Monetary Policy, Princeton University Press, 2003.

[54] Woodford, Michael, "Firm-Specific Capital and the New-Keynesian Phillips Curve," International Journal of Central Banking, 1(2), 2005

[55] Yun, Tack. "Nominal Price Rigidity, Money Supply Endogeneity and Business Cycles," Journal of Monetary Economics, 37(2), 1996. 
Figure 1: Response to a negative productivity shock, under the optimal and the zero inflation policy

(a) zero inflation

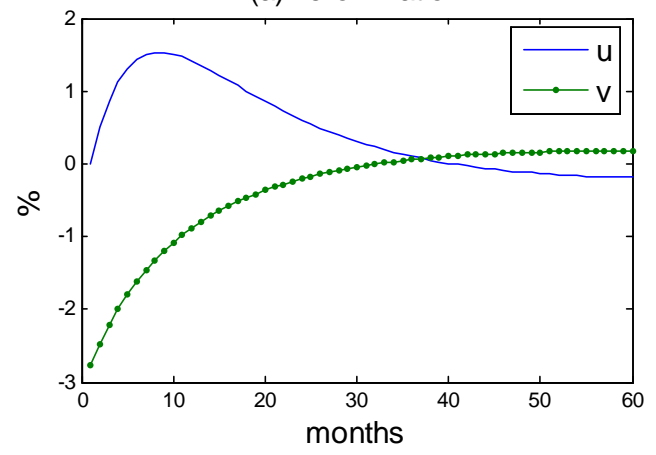

(b) zero inflation

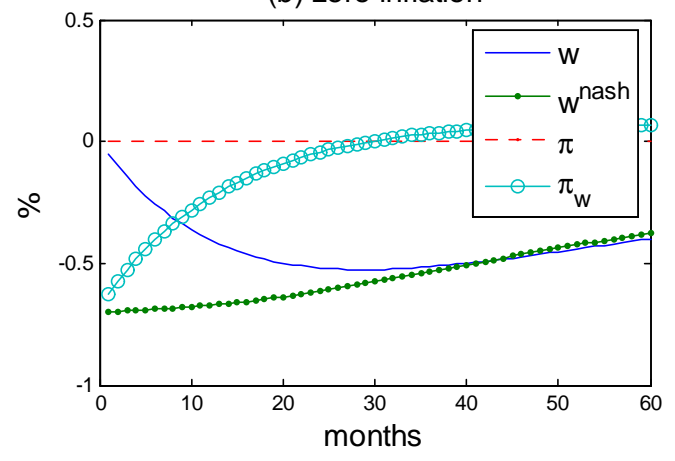

(c) optimal

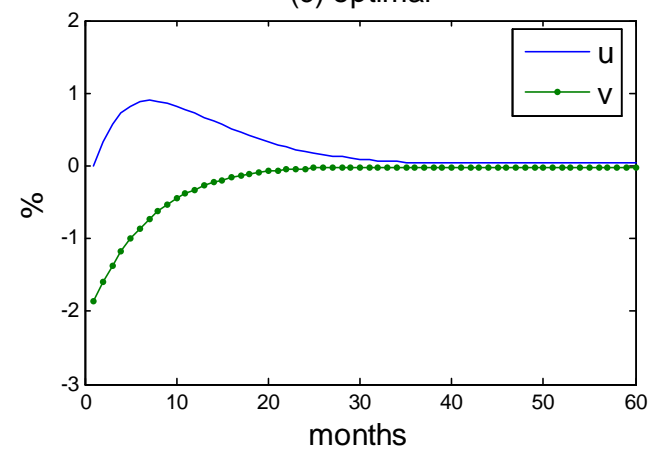

(d) optimal

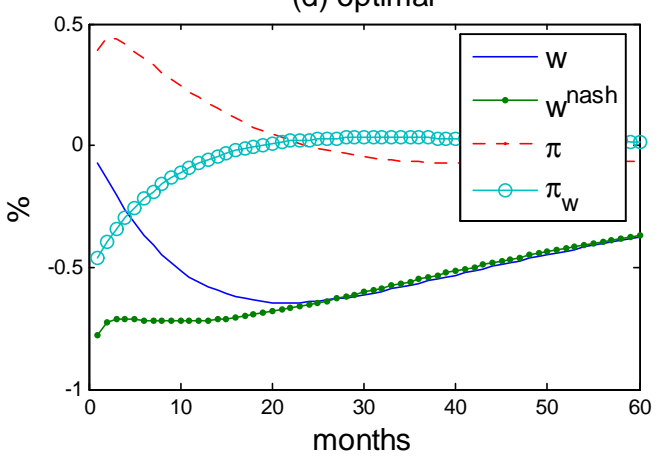


Figure 2: Response to a negative productivity shock in the social planner allocation

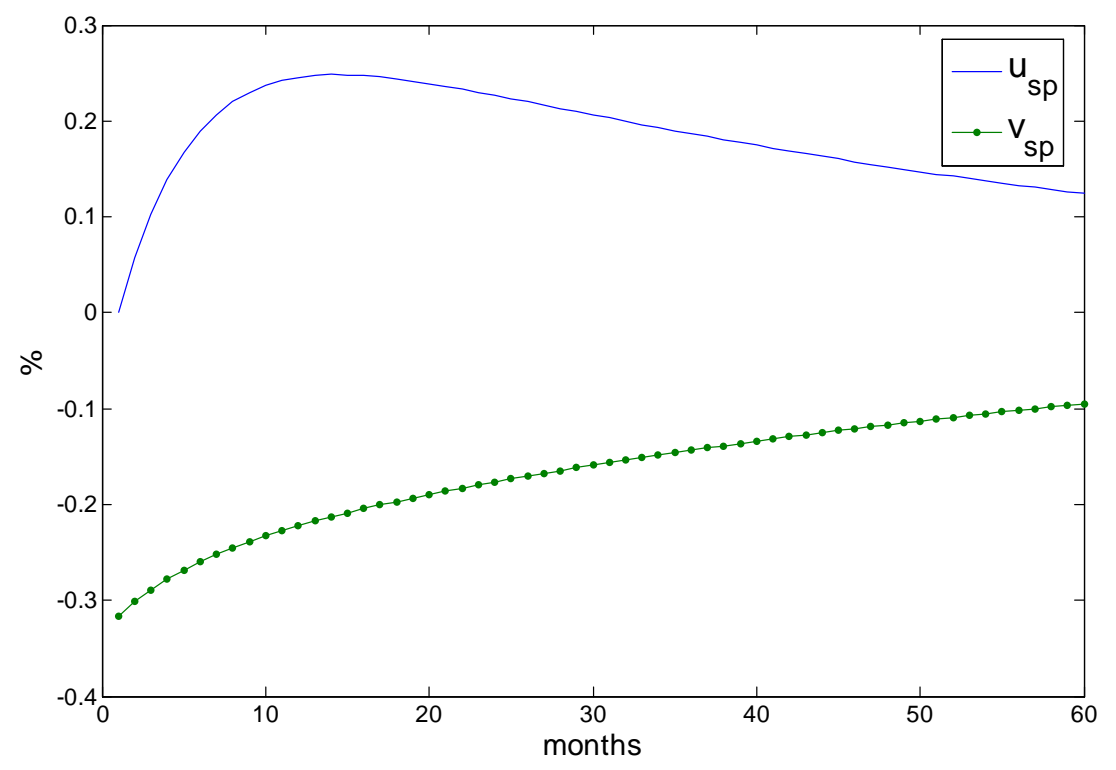

Figure 3: Unemployment response, net of response in the social planner allocation

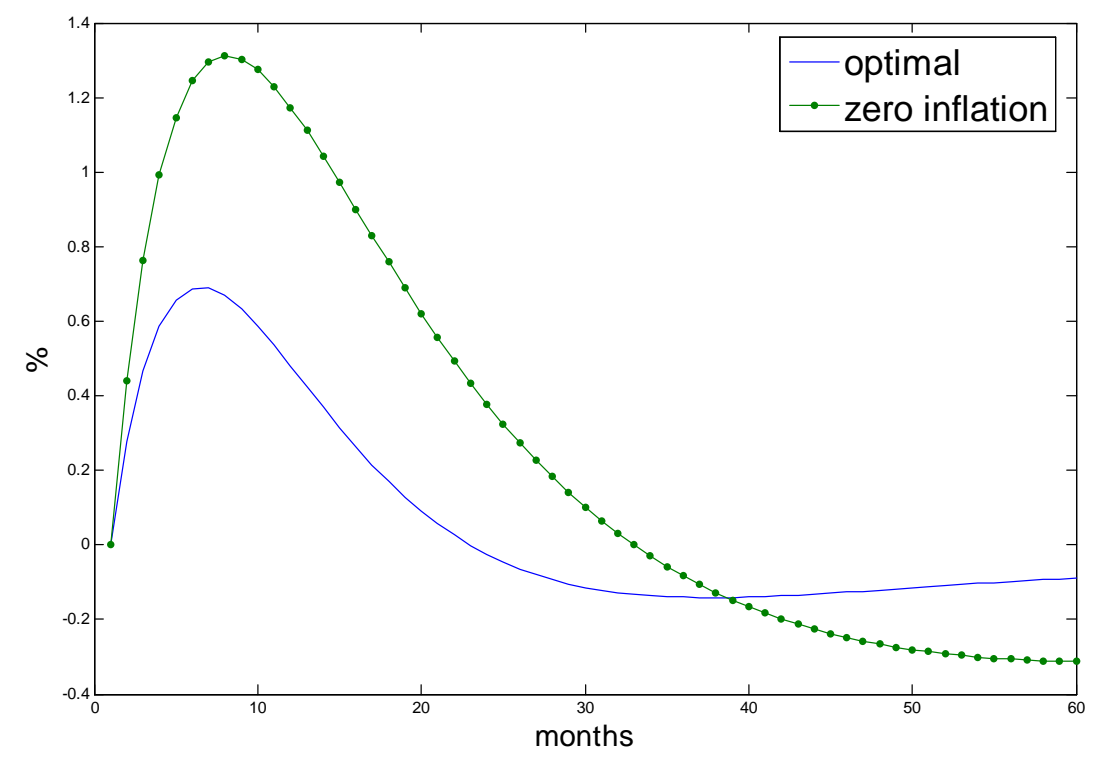


Figure 4: Net expected welfare loss under alternative policies

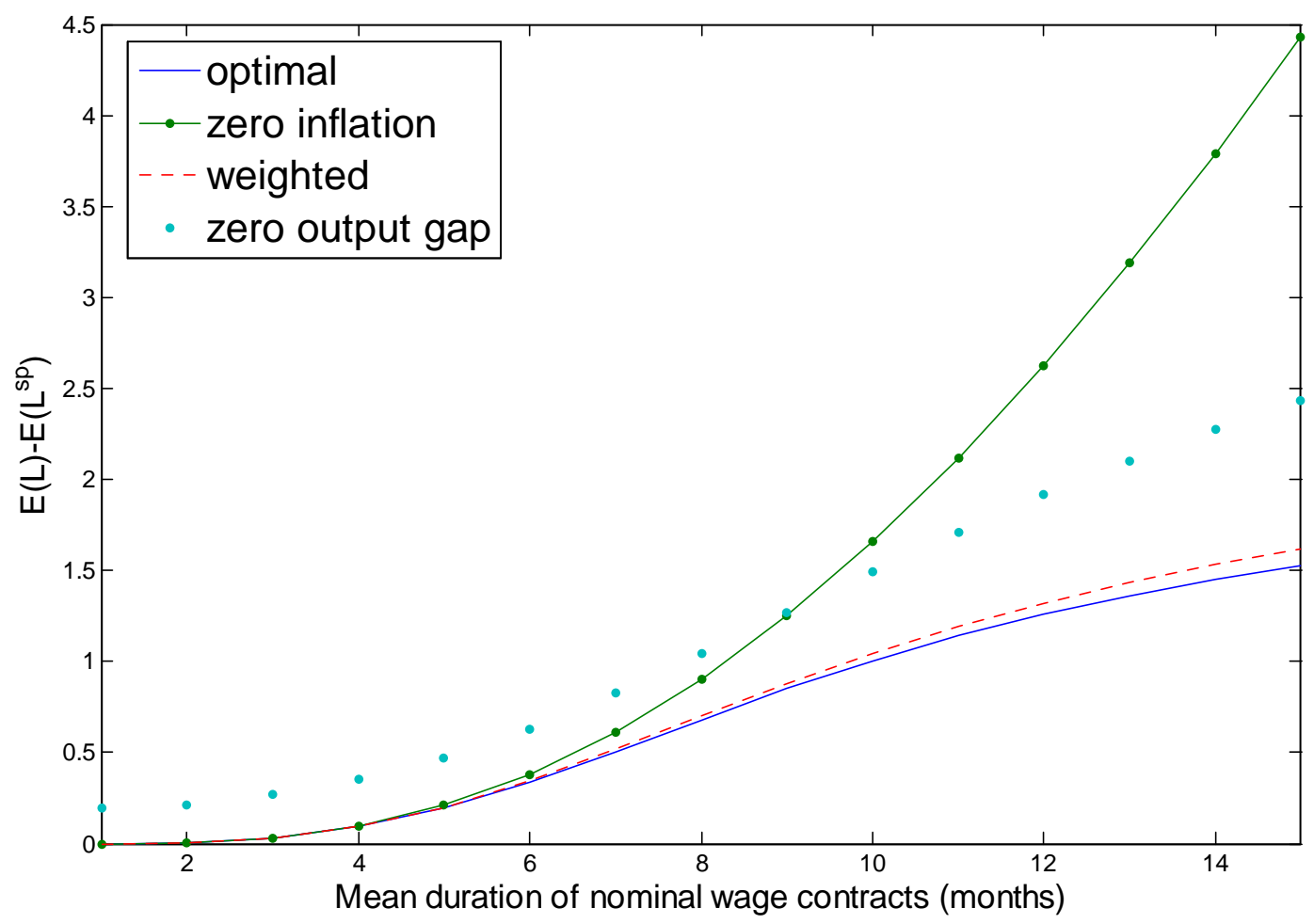


Figure 5: The bargaining set in firms that last changed the nominal wage 52 months ago, optimal policy

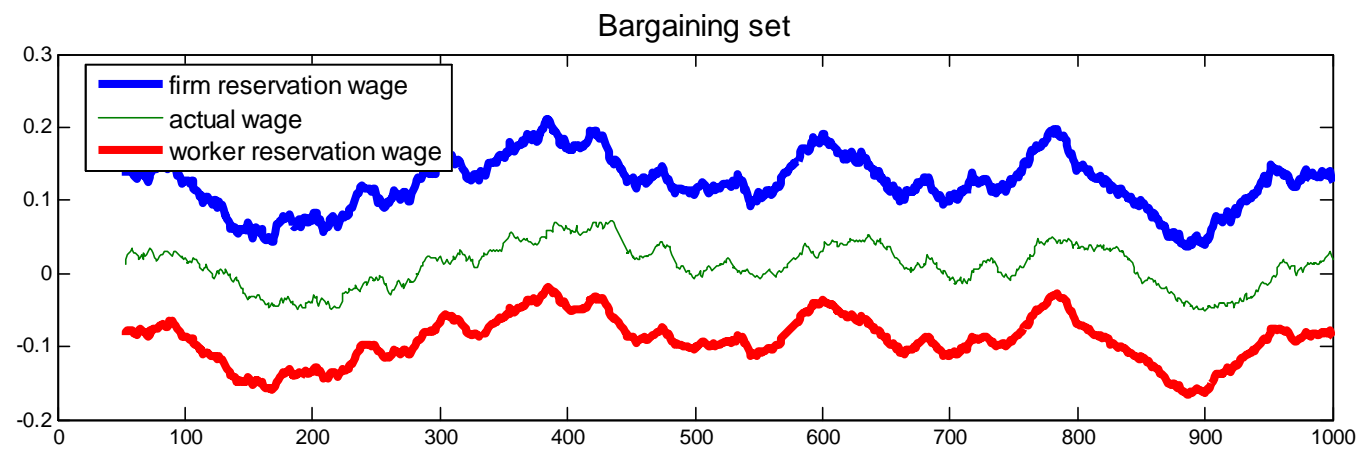

Firm and worker surplus

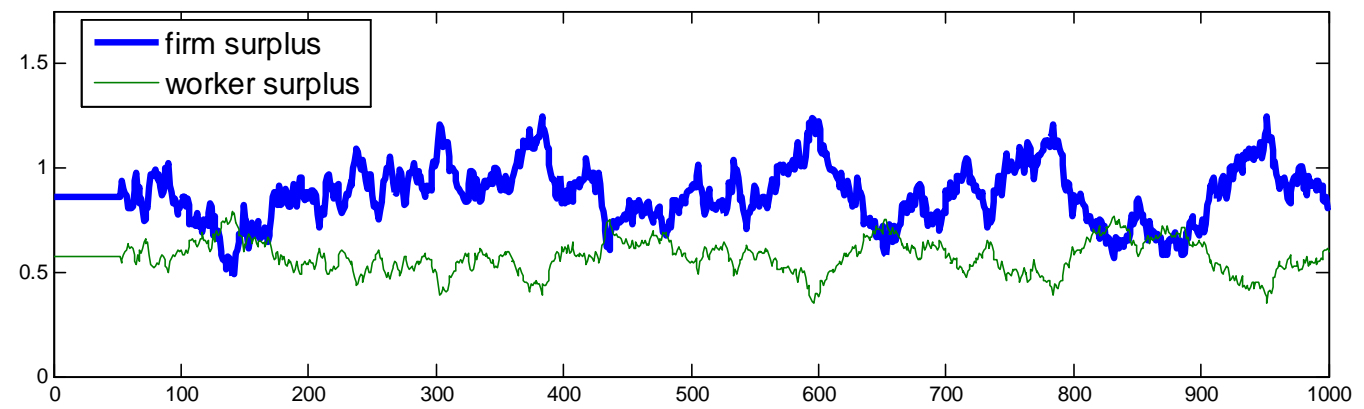


Figure 6: The bargaining set in firms that last changed the nominal wage 52 months ago, zero inflation policy

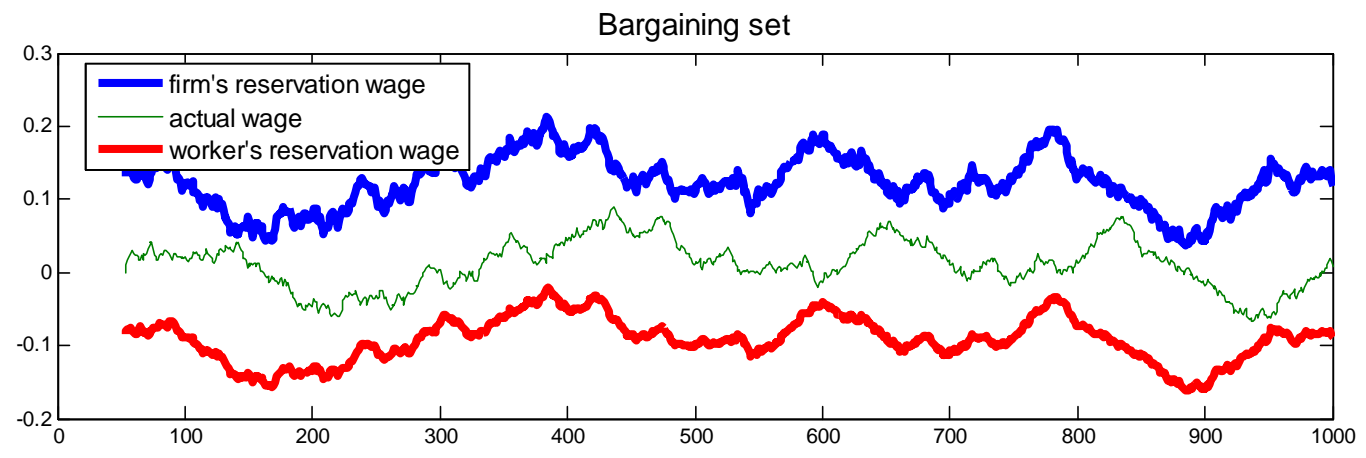

Firm and worker surplus

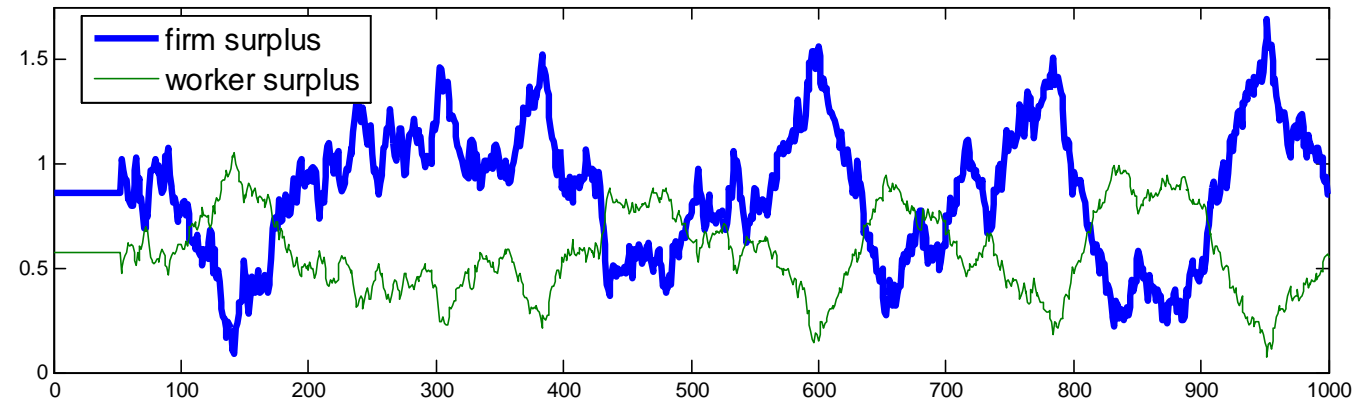


Figure 7: Net expected welfare loss under a lagged wage norm

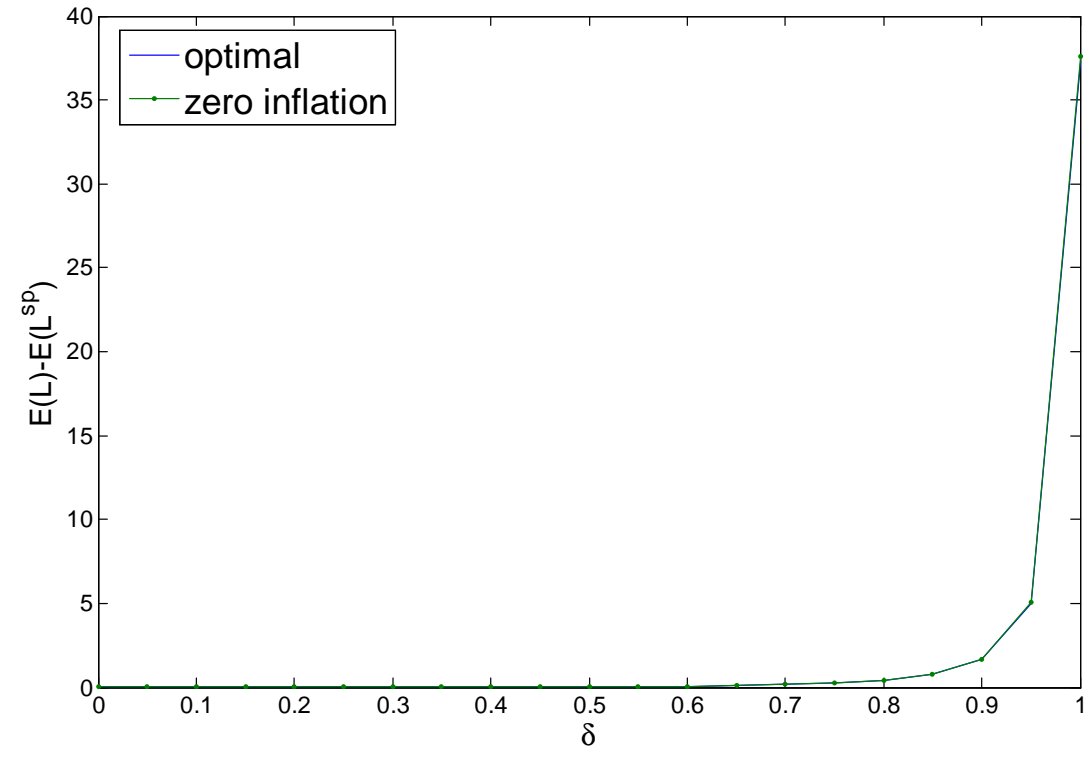

Figure 8: Net expected welfare loss under a constant wage norm

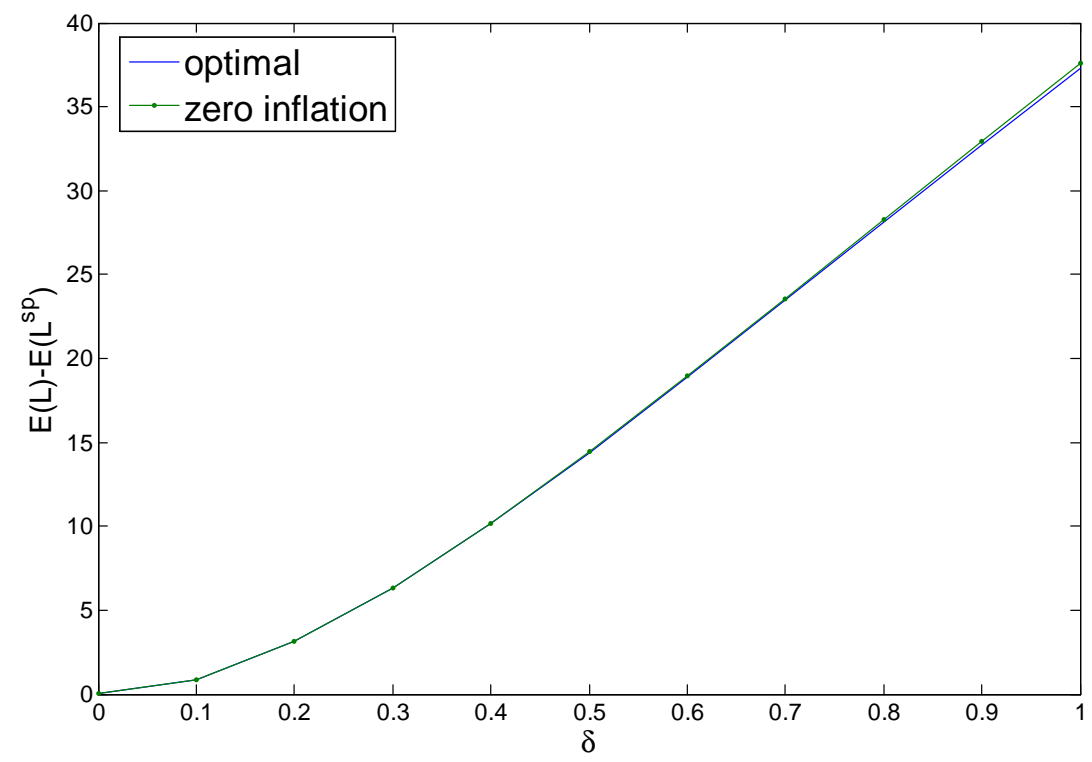




\section{CENTRE FOR ECONOMIC PERFORMANCE Recent Discussion Papers}

742 Tobias Kretschmer Katrin Muehlfeld

741 Francesco Caselli Nicola Gennaioli

740 Michael Noel Mark Schankerman

739 Nick Bloom

Stephen Bond

John Van Reenen

738 Sami Napari

737 Tobias Kretschmer

736 Andrew B. Bernard Stephen J. Redding Peter K. Schott

735 Francesco Caselli James Feyrer

734 Frédéric Robert-Nicoud

733 Alex Bryson Michael White

732 Francesco Caselli Wilbur John Coleman II

731 Alex Bryson Richard Freeman

730 Giulia Faggio Stephen Nickell
Co-Opetition and Prelaunch in Standard Setting for Developing Technologies

Dynastic Management

Strategic Patenting and Software Innovation

Uncertainty and Investment Dynamics

The Early Career Gender Wage Gap

Competing Technologies in the Database

Management Systems Market

Multi-Product Firms and Product Switching

The Marginal Product of Capital

Off-Shoring of Business Services and DeIndustrialization: Threat or Opportunity - and for Whom?

Unions, Within-Workplace Job Cuts and Job Security Guarantees

On the Theory of Ethnic Conflict

What Voice Do British Workers Want?

Patterns of Work Across the OECD 
729 Saul Lach

Mark Schankerman

728 Philippe Aghion

Robin Burgess

Stephen Redding

Fabrizio Zilibotti

727 Richard E. Baldwin

Fredéric Robert-Nicoud

726 Gustavo Crespi

Chiara Criscuolo

Jonathan Haskel

725 Giovanni Olivei

Silvana Tenreyro

724 Ghazala Yasmeen Azmat

723 Sharon Belenzon

722 Daron Acemoglu

Philippe Aghion

Claire Lelarge

John Van Reenen

Fabrizio Zillibotti

721 Sharon Belenzon

720 Rafael Gomez

Konstantinos Tzioumis

719 Ralph Ossa

718 Nick Bloom
The Impact of Royalty Sharing Incentives or

Technology Licensing in Universities

The Unequal Effects of Liberalization: Evidence from Dismantling the License Raj in India

Trade and Growth with Heterogeneous Firms

Productivity, Exporting and the Learning-byExporting Hypothesis: Direct Evidence from UK Firms

The Timing of Monetary Policy Shocks

The Incidence of an Earned Income Tax Credit:

Evaluating the Impact on Wages in the UK

Basic Research and Sequential Innovation

Technology, Information and the Decentralization of the Firm

Knowledge Flow and Sequential Innovation:

Implications for Technology Diffusion, R\&D and

Market Value

What Do Unions Do to CEO Compensation?

A Gold Rush Theory of Economic Development

The Impact of Uncertainty Shocks: Firm Level

Estimation and a 9/11 Simulation

The Centre for Economic Performance Publications Unit

Tel 02079557673 Fax 02079557595 Email info@cep.lse.ac.uk Web site http://cep.lse.ac.uk 